\title{
Performance analysis and modeling: atmospheric turbulence and crosstalk of WDM-FSO network
}

Ebrahim E. Elsayed ( $\nabla$ engebrahem16@gmail.com )

Electronics and Communications Engineering Department, Faculty of Engineering, Mansoura University, Mansoura 35516, El-Dakahilia Governorate, Egypt. https://orcid.org/0000-0002-7208-2194

\section{Research Article}

Keywords: WDM systems, Dense wavelength division multiplexing, Free-space optical communicationsAtmospheric turbulence, BER analysis

Posted Date: April 26th, 2021

DOI: https://doi.org/10.21203/rs.3.rs-460314/v1

License: (1) This work is licensed under a Creative Commons Attribution 4.0 International License. Read Full License 


\title{
Performance analysis and modeling: atmospheric turbulence and crosstalk of WDM-FSO network
}

\author{
Ebrahim E. Elsayed \\ Electronics and Communications Engineering Department, Faculty of Engineering, Mansoura University, \\ Mansoura 35516, El-Dakahilia Governorate, Egypt. \\ Author's email address: engebrahem16@gmail.com
}

\begin{abstract}
A wavelength division multiplexing (WDM) access network using high-speed free-space optical (FSO) communication for the distribution link is proposed. This Paper investigates terrestrial atmospheric of WDM-FSO communication systems operating under the influence of turbulence-induced scintillation, beam spreading, optical interchannel crosstalk, amplified spontaneous emission noise and pointing errors.On-off keying-non-return-to-zero and digital pulse position modulation are the modulation schemes used for the calculations.
\end{abstract}

Keywords-WDM systems; Dense wavelength division multiplexing; Free-space optical communications-Atmospheric turbulence, BER analysis.

\section{Introduction}

The passive optical network (PON) was experimented and standardized within the last two decades, and has topologically evolved at different times in attempt to open up the optical access networks. Compared to the copper-based access networks, the PON was major progress in providing higher bandwidth to the access networks [5].Nevertheless, further upgrade is desired in the optical access networks to avoid capacity saturation and adequately provide for the increasing traffic demands [28], and optical CDMA could provide the additional capacity. The WDM channels suffer from interchannel crosstalk, while the FSO communication performance in a clear atmosphere is limited by atmospherically induced scintillation. These impairments, plus the amplified spontaneous emission noise from optical amplification. Wavelength division multiplexing (WDM) systems allow more ONUs to be connected at high data rates and assign a distinct pair of dedicated wavelengths to each $\mathrm{ONU}$ to establish a point-to-point connection between the $\mathrm{ONU}$ and the optical line terminator (OLT) [5].

\section{Network structure}

A diagram of the proposed network is shown in Fig.1, the optical orthogonal codes (OOCs) are also used for this network. Each K users on the same wavelength use distinct OOCs from the same family, and a user corresponds to a single optical network unit (ONU) so both terms are used interchange ably in this analysis. In the downstream, coded signals are transmitted on multiple wavelengths from the optical line terminator (OLT) via a feeder fibre and distributed to individual ONUs by FSO link. At the ONUs, upstream coded signals are transmitted through a short fibre length and from a transmitting lens (TL) to the corresponding collecting lens (CL) at the remote node using the FSO link.

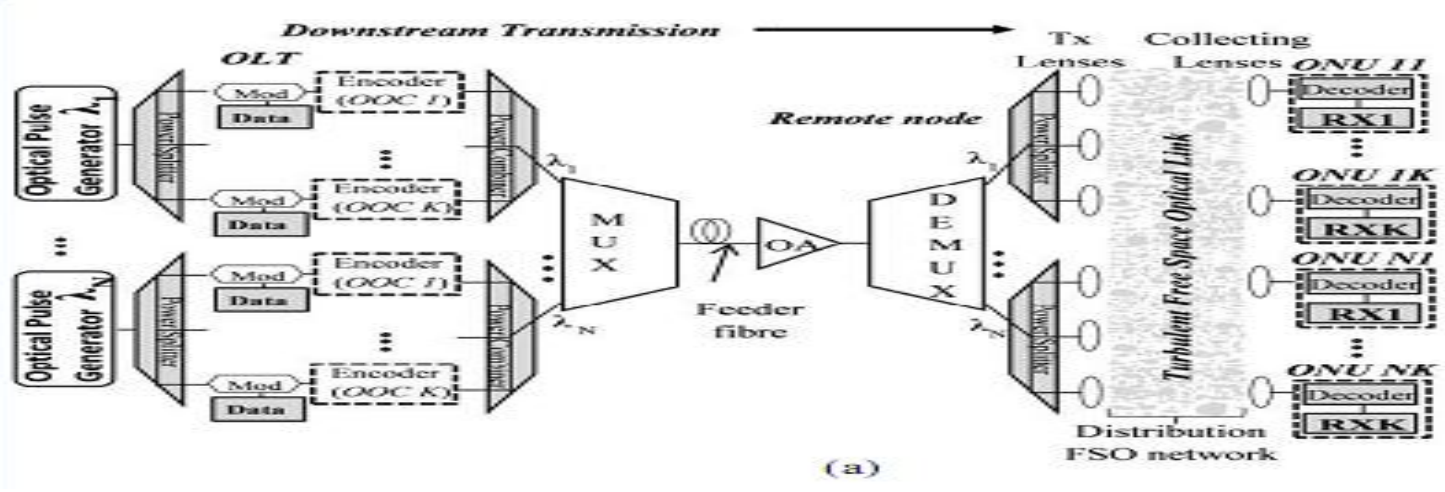




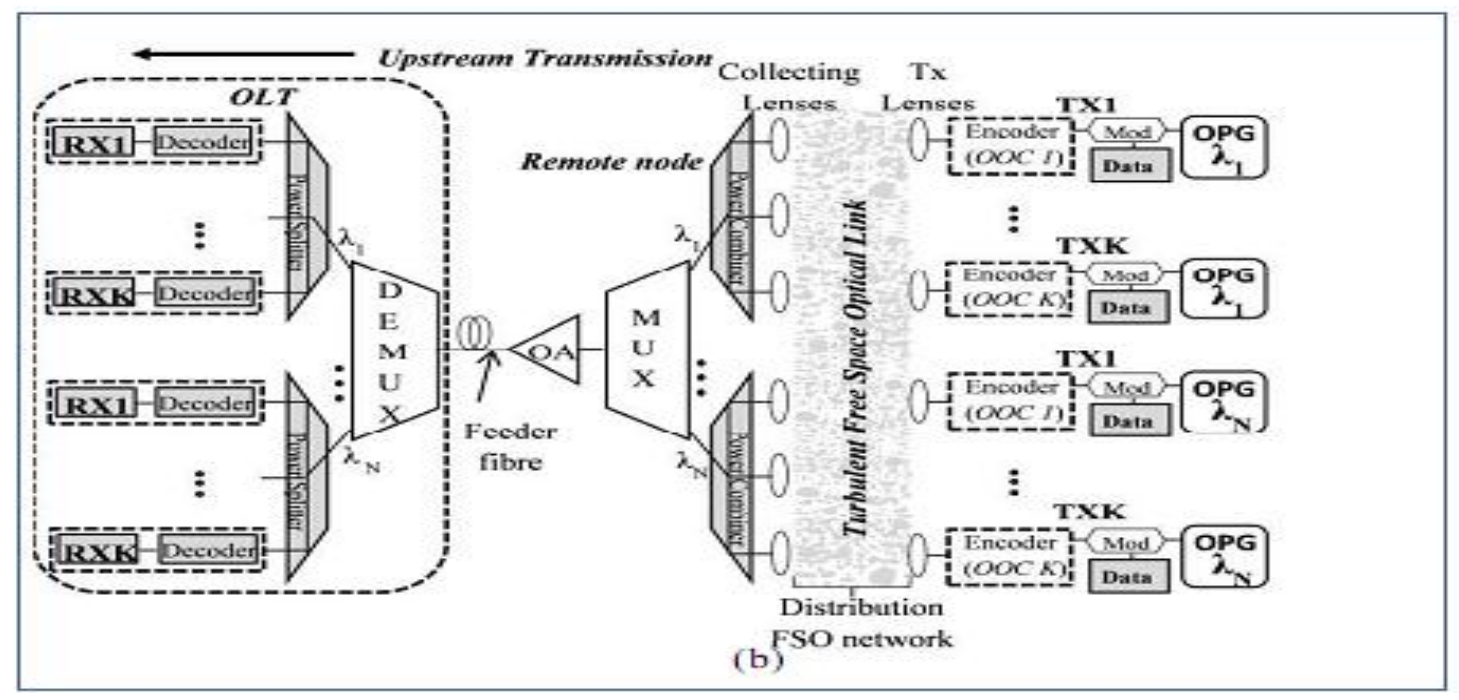

Fig.1 Hybrid WDM and OCDMA Network with Optical fibre and FSO links: (a) Downstream network diagram and (b) Upstream network diagram.

\section{Upstream transmission}

Multiple ONUs limited by the number of OOCs share a dedicated wavelength and establish a point-topoi $\mathrm{t}$ upstream transmission link with the OLT (seeFi.1b).The operating wavelengths are assumed to be set around $1550 \mathrm{~nm}$ on the C-band of the ITUT grid, thus benefiting from the low signal attenuation and developed optical device technology in those range of wavelengths. Each group of ONUs transmitting on a fixed wavelength uses the same laser transmitters operating at a set central wavelength. Optically encoded signals from the ONUs located a thomes, buildings or kerb are transmitted upstream through a turbulent FSO link to the remote node. The average optical received power at the OLT photodiode from an ONU on the desired signal wavelength and an ONU on the crosstalk wavelength are respectively written as [18-30].

$$
\begin{gathered}
P_{d}\left(h_{d}\right)=G P_{T U, d} h_{d} L_{f s, d} L_{b s, d} \eta_{c, d} L_{S .2} L_{m u x} L_{f} L_{d e m u x} \\
P_{i}\left(h_{i}\right)=G P_{T U, i} h_{i} L_{f s, i} L_{b s, i} \eta_{c, i} L_{S .2} L_{m u x} L_{f} L_{d e m u x} L_{d e m u x, i}
\end{gathered}
$$

Where $P_{T U, d}$ and $P_{T U, i}$ are the transmit power of an $O N U$ on the desired signal wavelength and an $\mathrm{ONU}$ on the crosstalk Wavelength respectively, and $L_{s, j}$ is the total loss for $\boldsymbol{j}$ number of power spiltters or combiners. The single polarization ASE power spectral density (PSD) at the OLT photodetector inputs from an $O N U$ on the desired signal wavelength and an $O N U$ on the crosstalk wavelength are respectively written as [18 -30].

$$
\begin{gathered}
N_{\circ}=0.5(N F \times G-1) h v L_{f} L_{S, i} L_{d e m u x} \\
N_{o, i=} 0.5(N F \times G-1) h v_{i} L_{f} L_{S, i} L_{\text {demux }} L_{\text {demux }, i}
\end{gathered}
$$

Where $G$ and $N F$ are the optical amplifier gain and noise figure respectively, $h$ is Plank's constant, $v$ and $v_{i}$ are the optical frequencies of the desired signal and crosstalk signal respectively. 


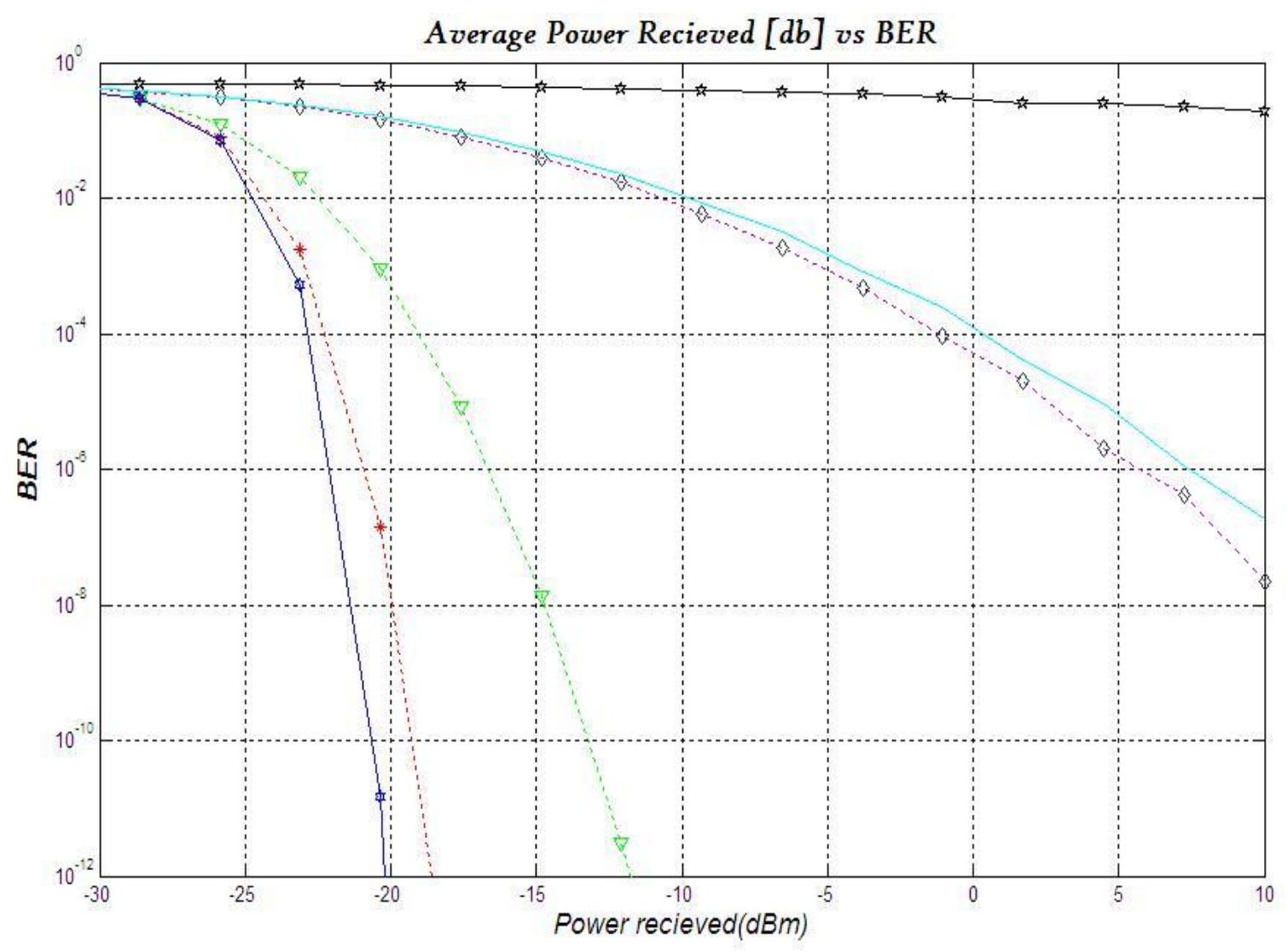

Fig.2: Power received vs BER in upstream transmission.

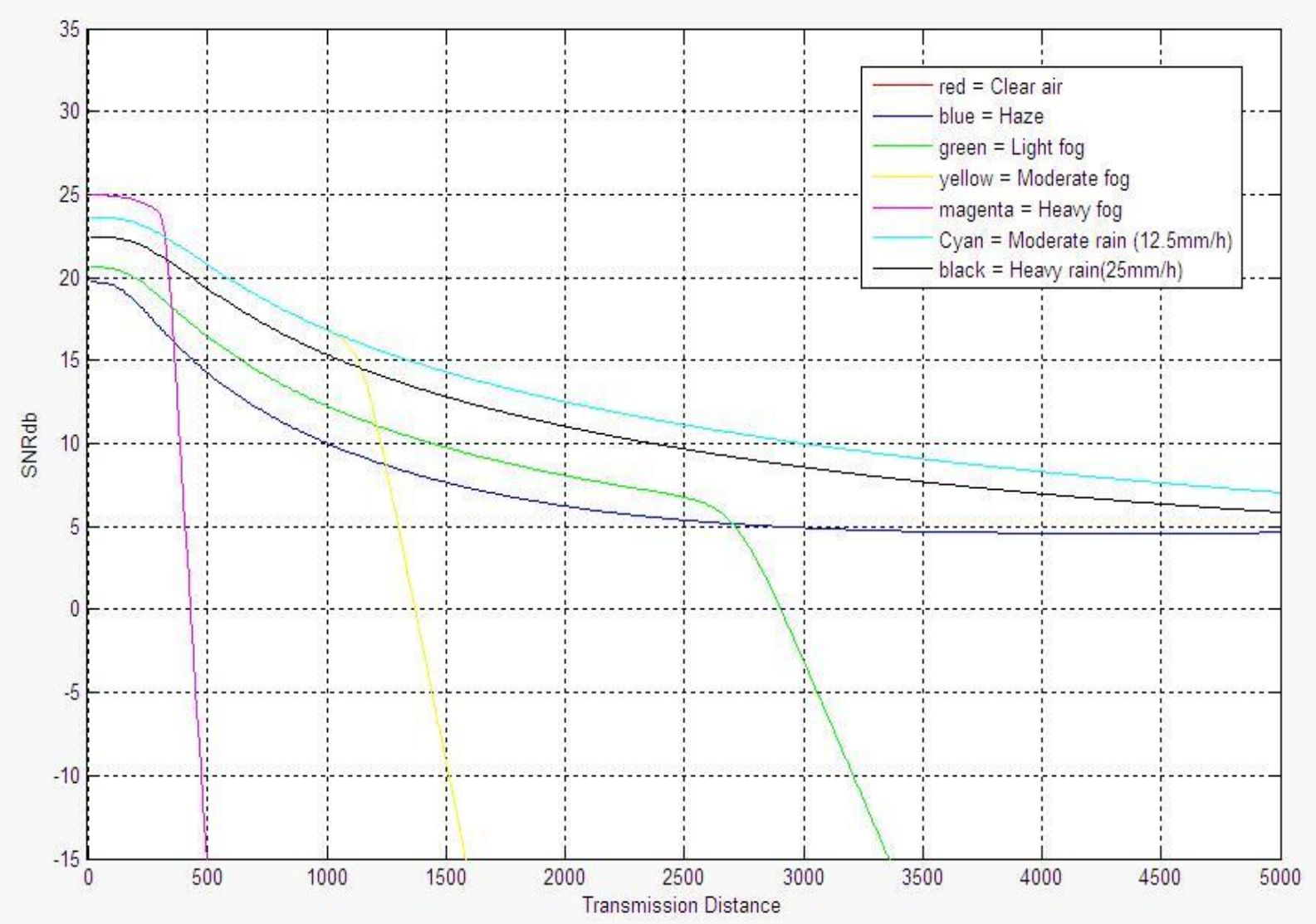

Fig.3: Transmission distance L_fso $=5 \mathrm{~km}$ vs Signal to-Noise ratio in upstream transmission 


\section{Downstream transmission}

The downstream architecture is similar to the upstream but the system operation is different. Each wavelength at the OLT has a separate laser source which transmits the signal for the group of ONUs on its wavelength. As shown in Fig.1a, the signal on each wavelength is split into the number of ONUs on the wavelength and separately encoded with the OOC for each ONU before being recombined for wavelength multiplexing [18-30]. The multiplexed signals propagates through the feeder fibre to the remote node for optical amplification and demultiplexing before each wavelength's signal is split into each ONUs signal and further transmitted through the FSO link for decoding and reception [30-35].

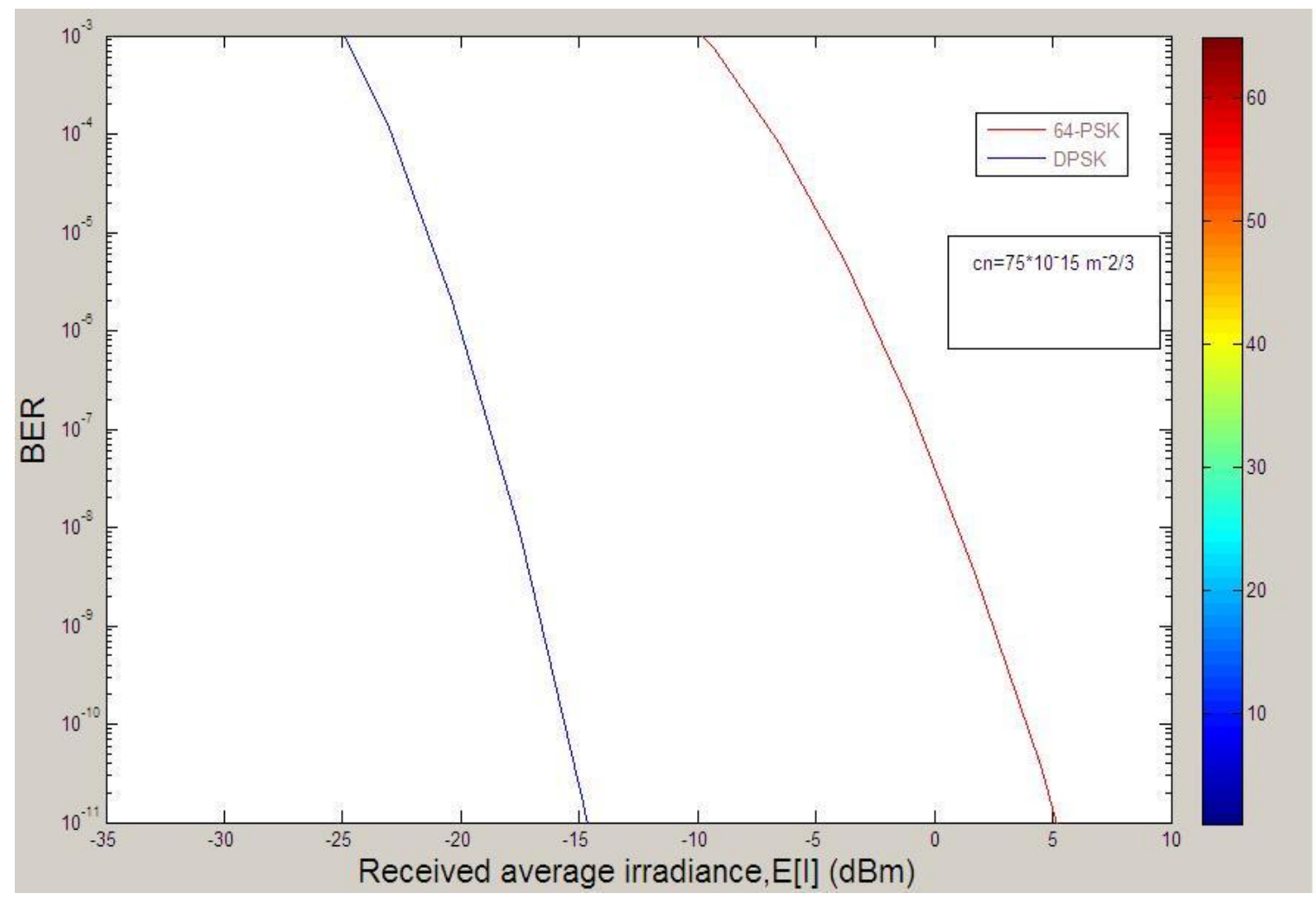

Fig.4: Received average irradiance [I] vs BER in downstream transmission. 


\section{TURBULENCE MODELING}

Atmospheric scintillation occurs due to thermally induced refractive index changes of the air along the optical link, causing rapid fluctuation of signal irradiance at the receiver, reduction in degree of coherence of the optical signal [34], and potentially poor bit error rate(BER).The gamma-gamma(GG) distribution is widely used for characterizing the whole range of turbulence effects ,i.e., weak, moderate, and strong, not only because closed form expressions exist but also because of their direct dependence on turbulence parameters and the closeness to experimental results $[14,16,18-30]$.

$P_{G G}\left(h_{X}\right)=\frac{2(\alpha \beta)^{(\alpha+\beta)} / 2}{\Gamma(\alpha) \Gamma(\beta)} h_{X}{ }^{(\alpha+\beta)} / 2-1 K_{\alpha-\beta}\left(2 \sqrt{\alpha \beta h X) ;} \quad h_{X}>0\right.$,

Where $h_{X}$ is the attenuation due to atmospheric turbulence for the signal $\left(\left(h_{s i g}\right)\right.$ or interferer $\left(h_{\text {int }}\right), \alpha$ is the effective number of large-scale eddies of the scattering process, $\beta$ is the effective number of small-scale eddies of the scattering process, $K_{n}(\cdot)$ is the gamma function. The signal and interferer travel over physically distinct paths in the upstream [30-35].

$$
\begin{aligned}
& \alpha=\left\{\exp \left[\frac{0.49 \sigma_{R}^{2}}{\left(1+0.65 d^{2}+1.11 \sigma_{R}^{12 / 5}\right)^{\frac{7}{6}}}\right]-1\right\}^{-1}, \\
& \beta=\left\{\exp \left[\frac{0.51 \sigma_{R}^{2}\left(1+0.69 \sigma_{R}^{12 / 5}\right)^{-5 / 6}}{1+0.9 d^{2}+0.62 d^{2} \sigma_{R}^{12 / 5}}\right]-1\right\}^{-1},
\end{aligned}
$$

Where $\mathrm{d}=\sqrt{K D_{R X}^{2} / 4 l_{f s o}}$ is the normalized RCL radius, $\sigma_{R}^{2}=1.23 C_{n}^{2} K^{7 / 6} l_{f s o}^{11 / 6}$ is the Rytov variance [18], $C_{n}^{2}$ is the refractive index structure constant (ranging from $10^{-17} \mathrm{~m}^{-2 / 3}$ to $\left.\sim 10^{-13} \mathrm{~m}^{-2 / 3}\right), l_{f s o}$ is the FSO link length, $\mathrm{k}=2 \pi / \lambda$ is the wave number [25-30]. 


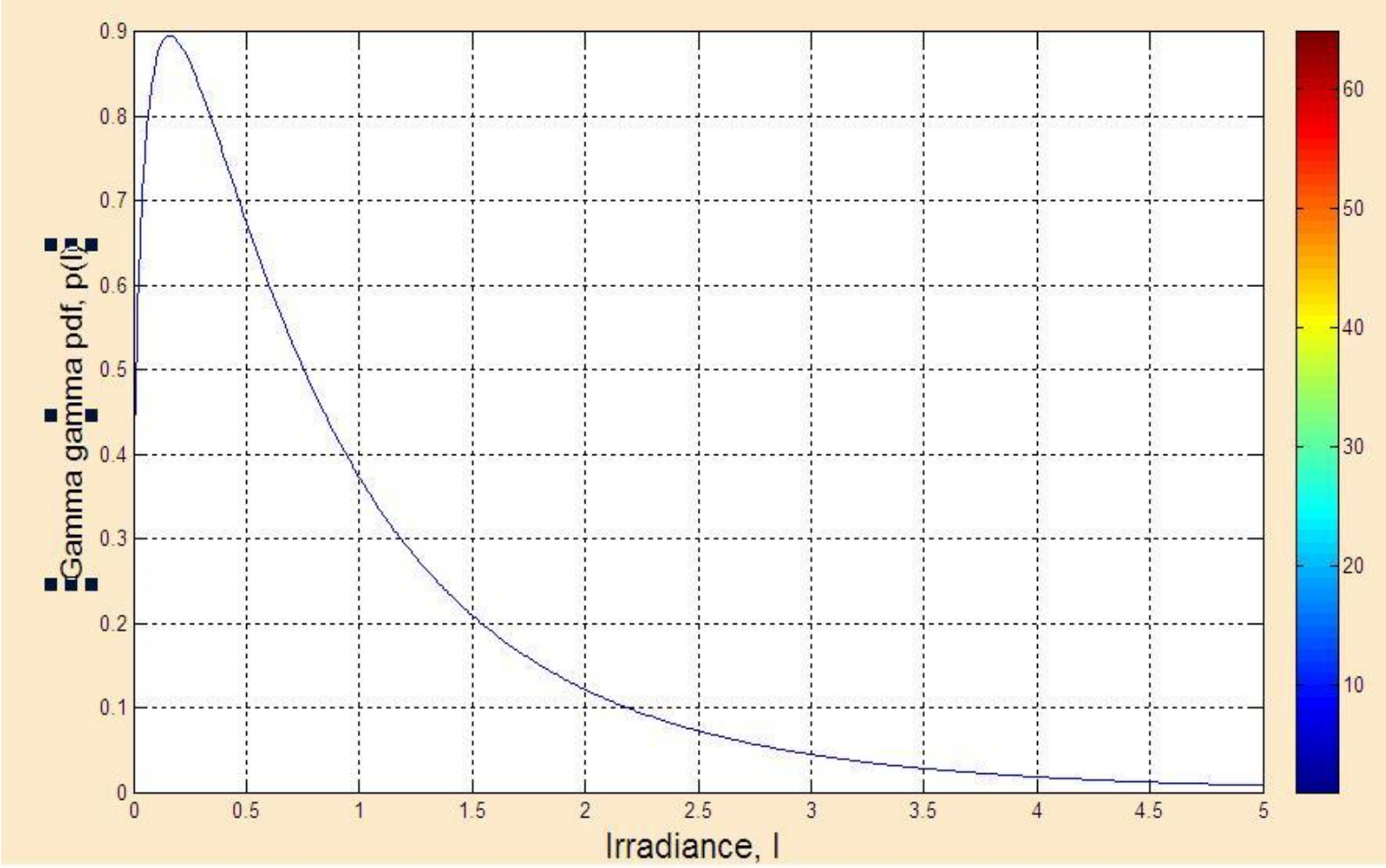

Fig.5: Log-normal pdf with $\mathrm{E}[\mathrm{I}]=1$ for a range of log irradiance variance $\sigma_{I}^{2}$.

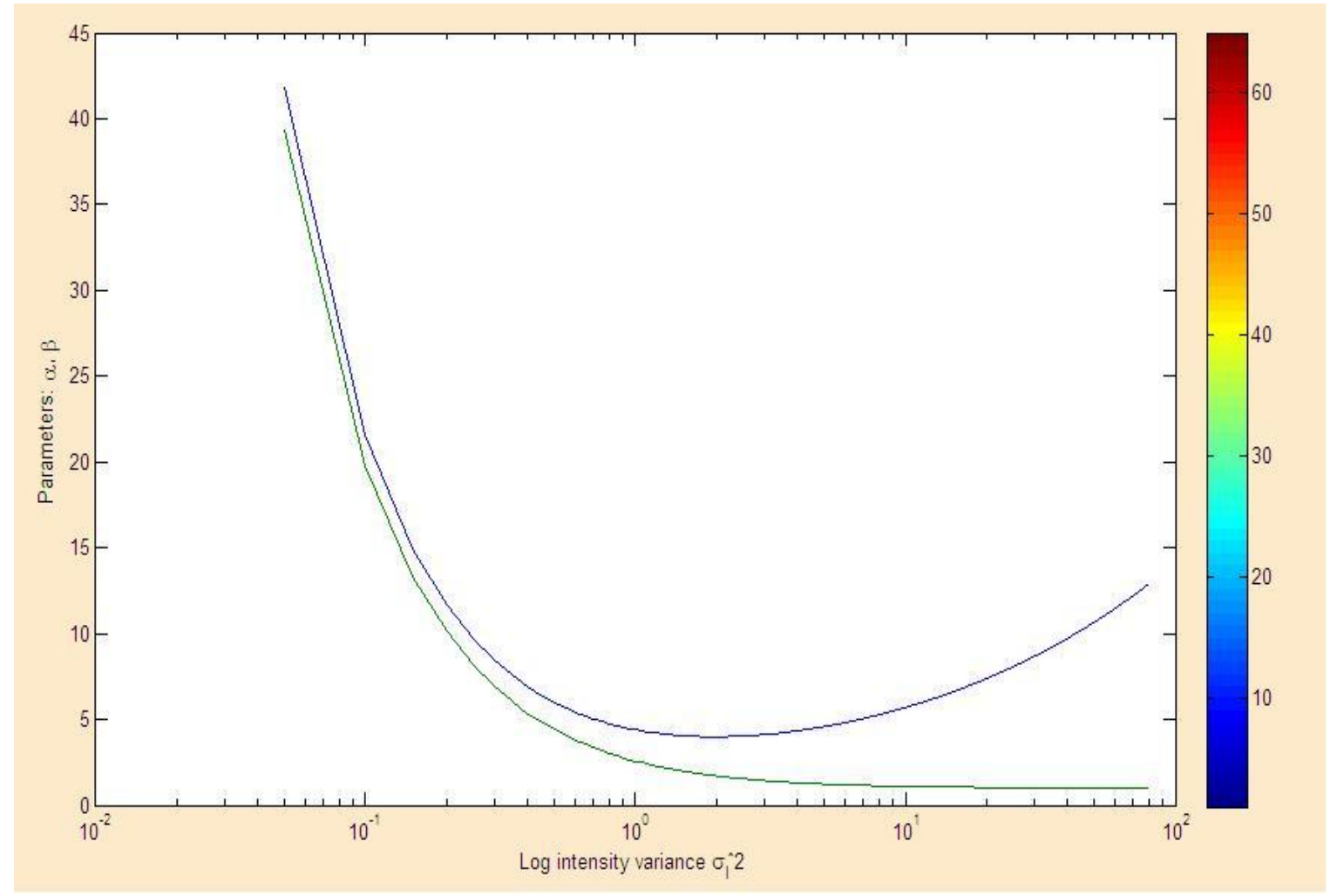

Fig.6: Values of $\alpha$ and $\beta$ under different turbulence regimes: weak, moderate to strong and saturation. 


\section{BER Analysis}

In its most general form,under the assumption of independent signal and crosstalk channels (e.g.,as in the upstream), the average (turbulence-accentuated)

BER [for given fixed transmitter powers for the signal and crosstalk [18].

\section{$\overline{B E R}=\iint_{0}^{\infty} B E R\left(h_{s i g}, h_{i n t}\right) P_{G G, s i g}\left(h_{s i g}\right) \times P_{G G, i n t}\left(h_{i n t}\right) d h_{s i g} d h_{i n t}$,}

Where $P_{G G, s i g}\left(h_{s i g}\right)$ and $P_{G G, s i g}\left(h_{\text {int }}\right)$ are respectively, the signal and interferer GG pdfs ( each with different $\alpha, \beta$ and $\sigma_{R}^{2}$ ).

$B E R\left(h_{s i g}, h_{i n t}\right)=\frac{1}{4} \operatorname{erfc}\left(\frac{Q\left(h_{\text {sig }}, h_{\text {int }}\right.}{\sqrt{2}}\right)$

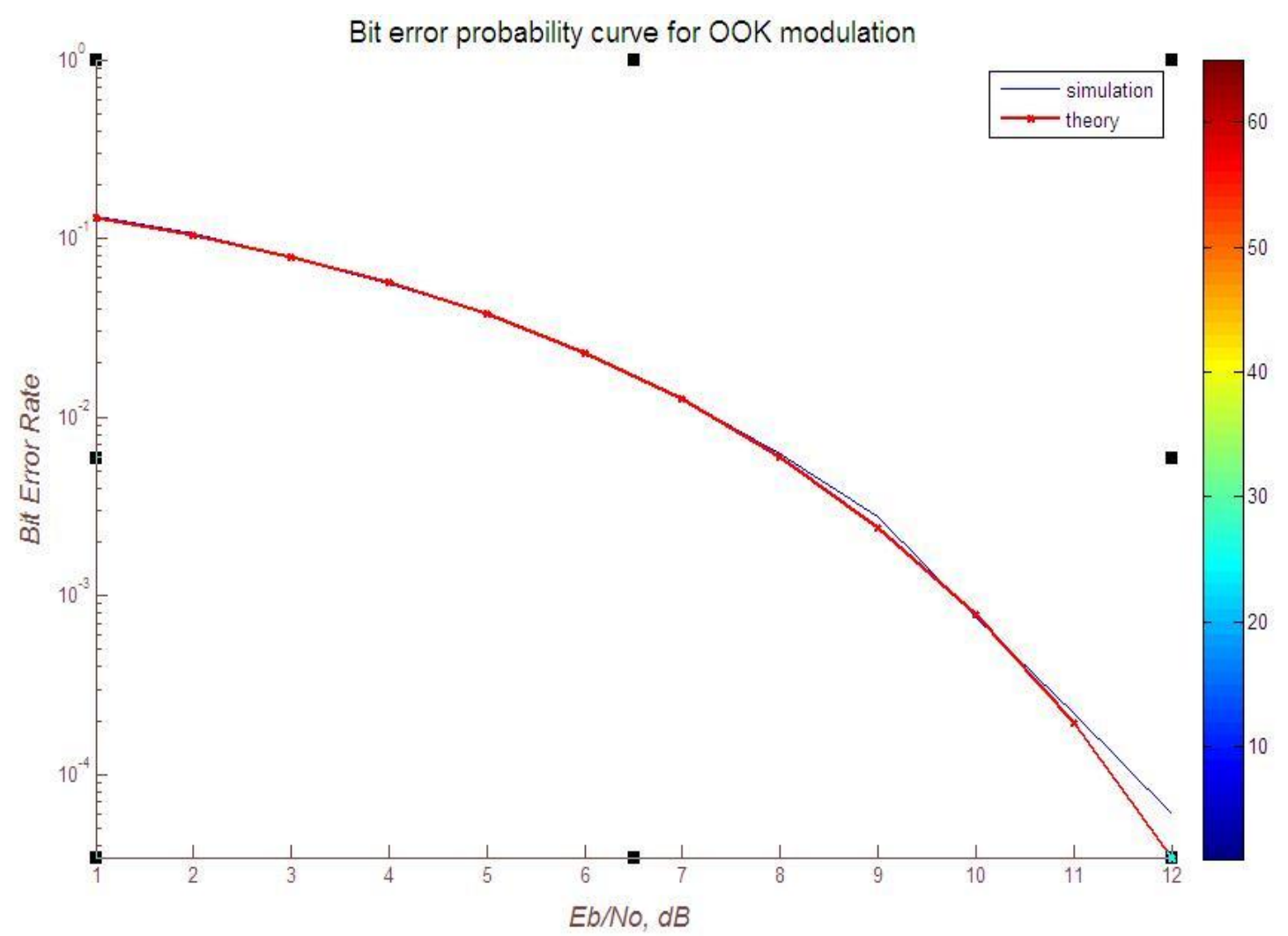

Fig.7: Bit error probability curve for OOK modulation. 


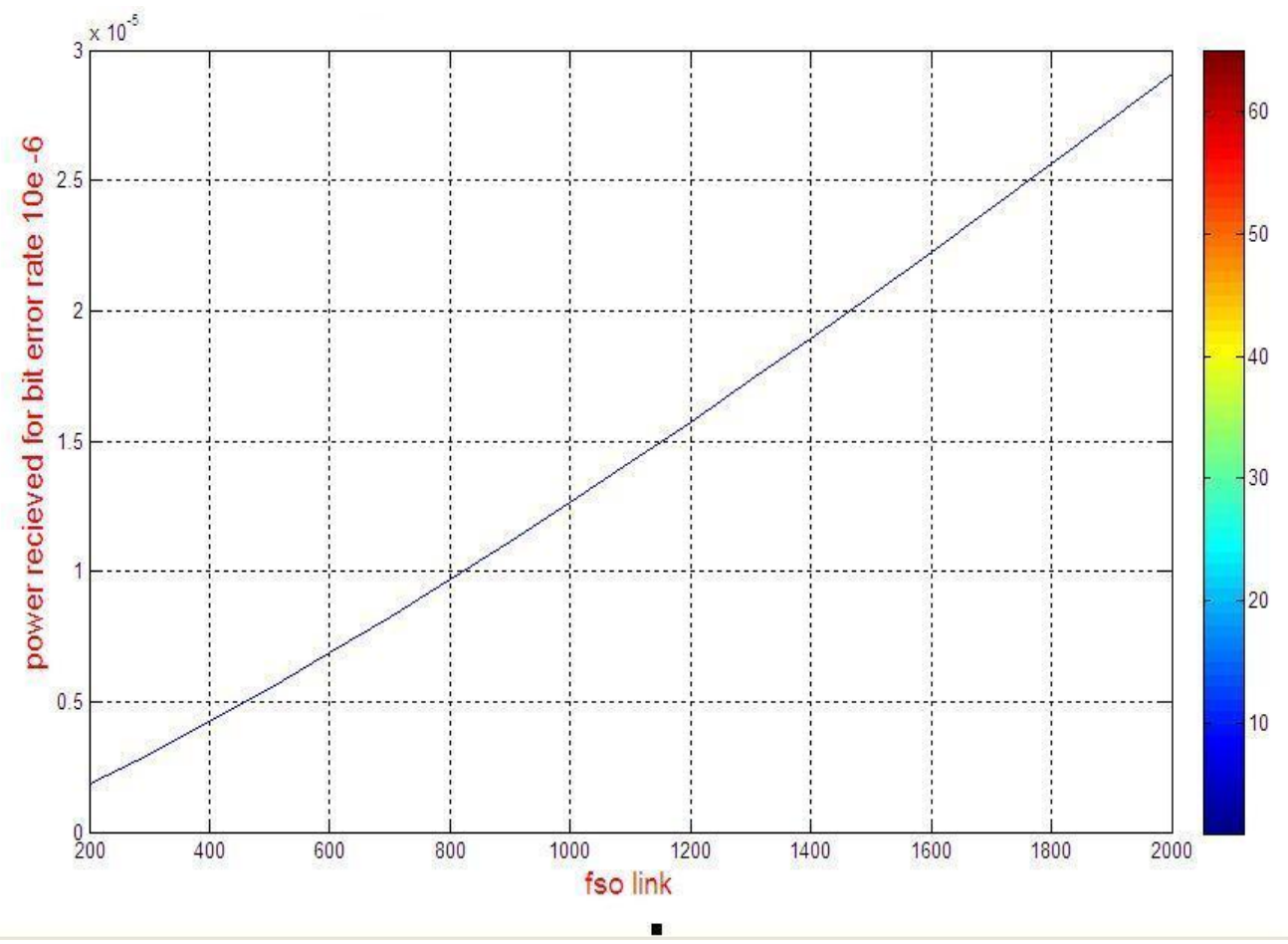

Fig.8: FSO Link Length (m) vs Power received (dBm) at BER $10^{-6}$.

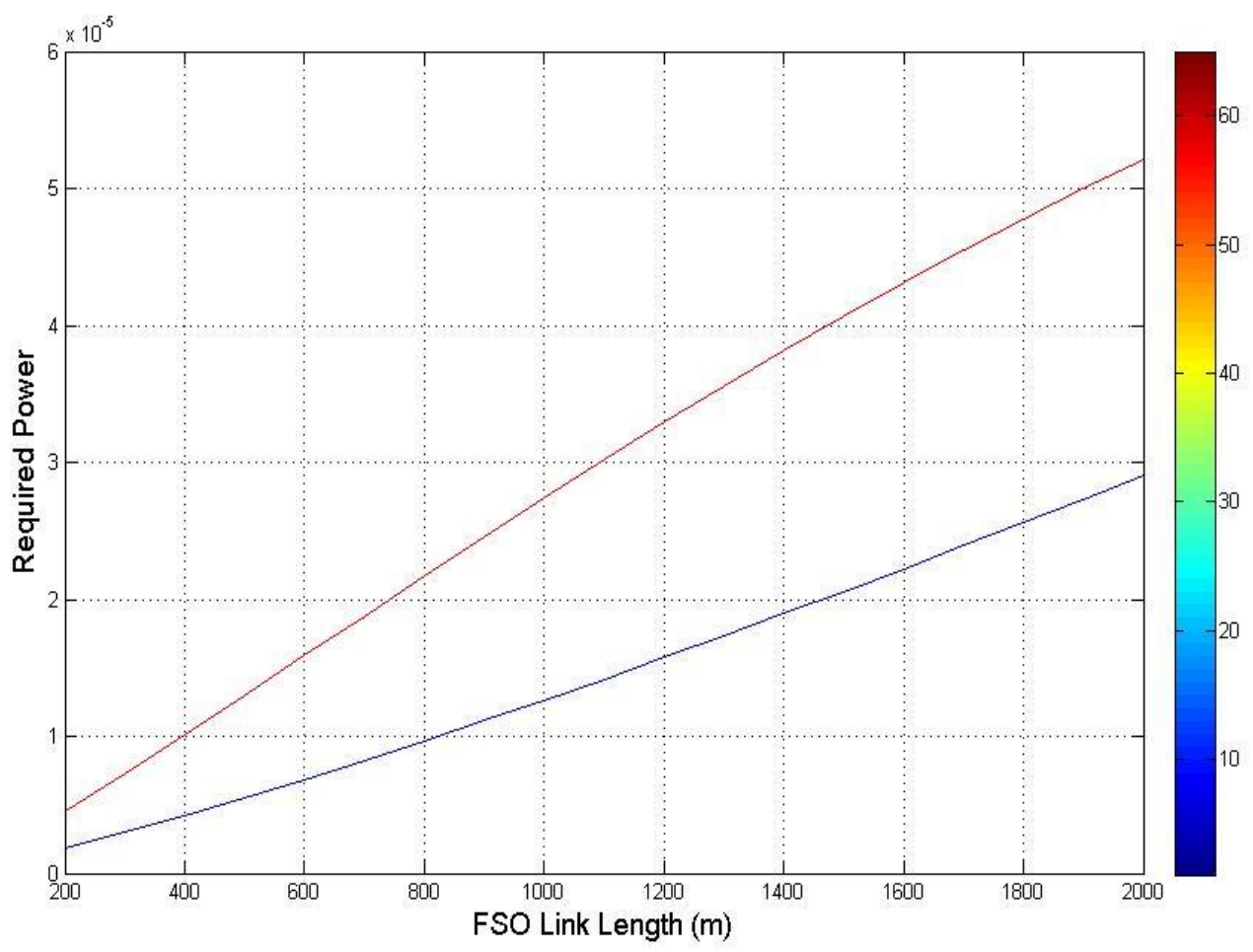

Fig.9: FSO Link Length (m) vs Power received (dBm) at BER $10^{-6}$. 


\section{Pulse Position Modulation}

In LOS OWC links where the requirement for the bandwidth is not of a major concern, PPM with its significantly better power efficiency seems to be the most attractive option for a range of applications PPM is an orthogonal modulation technique and a member of the pulse modulation family (see Figure 10). The PPM modulation technique improves on the power efficiency of OOK but at the expense of an increased bandwidth requirement and greater complexity.

In order to achieve the same throughput as OOK, PPM slot duration $T_{S, P P M}$ is shorter than the OOK bit duration $T_{b}$ by a factor L/M that is [16].

$$
T_{S_{-} P P M}=\frac{T_{b} M}{L}
$$

The transmit pulse shape for L-PPM is given by [16].

$$
x(t)_{P P M}=\left\{\begin{array}{cc}
1 & \text { for } t \in\left[(m-1) T_{S_{P P M}}, m T_{S_{P P M}}\right] \\
0 & \text { else where }
\end{array}\right\}
$$

Where $\mathrm{m} \in\{1,2, \ldots . L\}$.

Hence, the PPM symbol sequence is given by

$$
\mathbf{x}(\mathbf{t})_{\mathrm{PPM}}=\mathbf{L} \mathbf{P}_{\mathrm{t}} \sum_{\mathrm{k}=\mathbf{0}}^{\mathrm{L}-\mathbf{1}} \mathrm{C}_{\mathrm{k}} \mathbf{p}\left(\mathrm{t}-\frac{\mathrm{KT}_{\text {symb }}}{\mathrm{L}}\right)
$$

Where $C_{k} \in\left\{c_{0}, c_{1}, c_{2}, \ldots, c_{L}\right\}$ is the PPM symbol sequence, $p(t)$ is the pulse shaping function of unity height and of duration $T_{\text {sysmb }} / L, T_{\text {sysmb }}\left(=T_{b} M\right)$ is the symbol interval and $L P_{a v g}$ is the peak optical power of PPM symbol. 


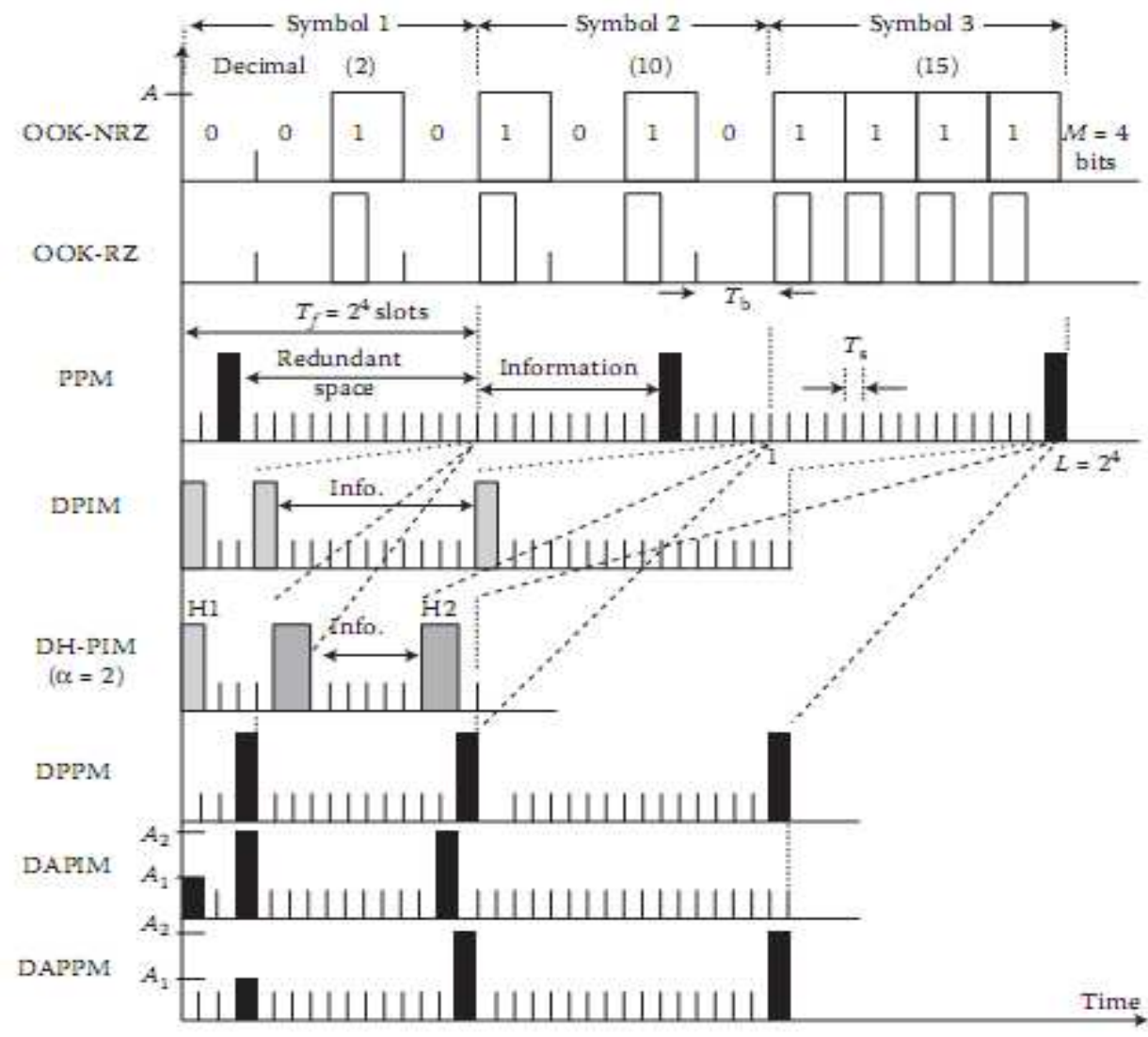

Fig.10: Time waveforms for OOK, PPM, DPI, DH-PIM, DPPM, DAPIM and DAPPM signals.

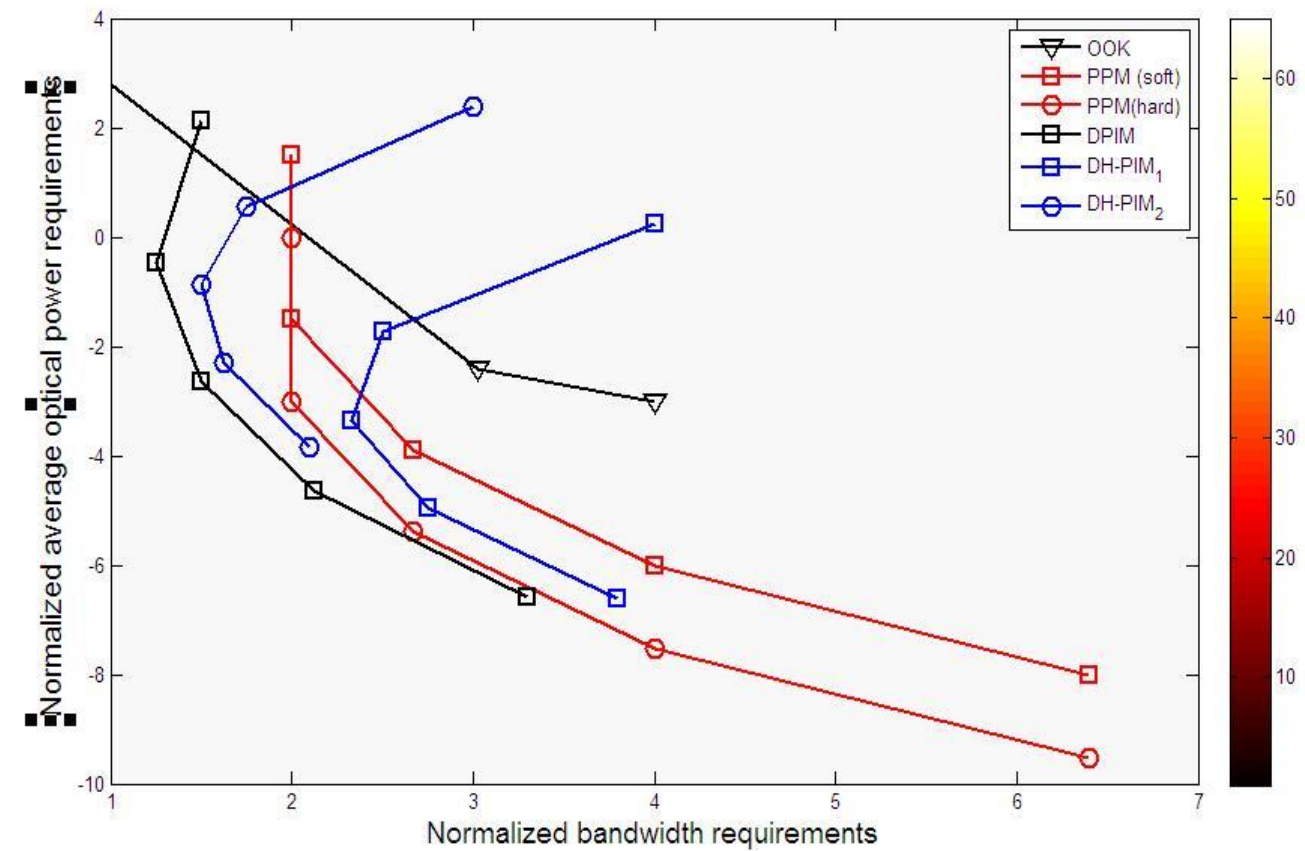

Fig.11: Optical power requirement normalized to the OOK-NR versus bandwidth requirement normalized to the bit rate for OOK, PPM, PIM, DH-PIM 1 and $D P I M_{2}$, The numbers indicate the values of $\mathrm{L}$. 


\section{FSO Link Performance under the Effect of Atmospheric Turbulence.}

Atmospheric turbulence is known to cause signal fading in the channel. There are many different types of modulation schemes that are suitable for optical wireless communication systems. The effect of atmospheric turbulence-induced fading on the following techniques: on-off keying (OOK), pulse position modulation (PPM) and phase shift keying pre-modulated subcarrier intensity modulation [16]. The classical modulation technique used for FSO is OOK $[1,2]$. This is primarily because of the simplicity of its design and implementation. The PPM requires no adaptive threshold and is predominantly used for deep space free-space optical communication links because of its enhanced power efficiency compared to the OOK signaling [5-10].

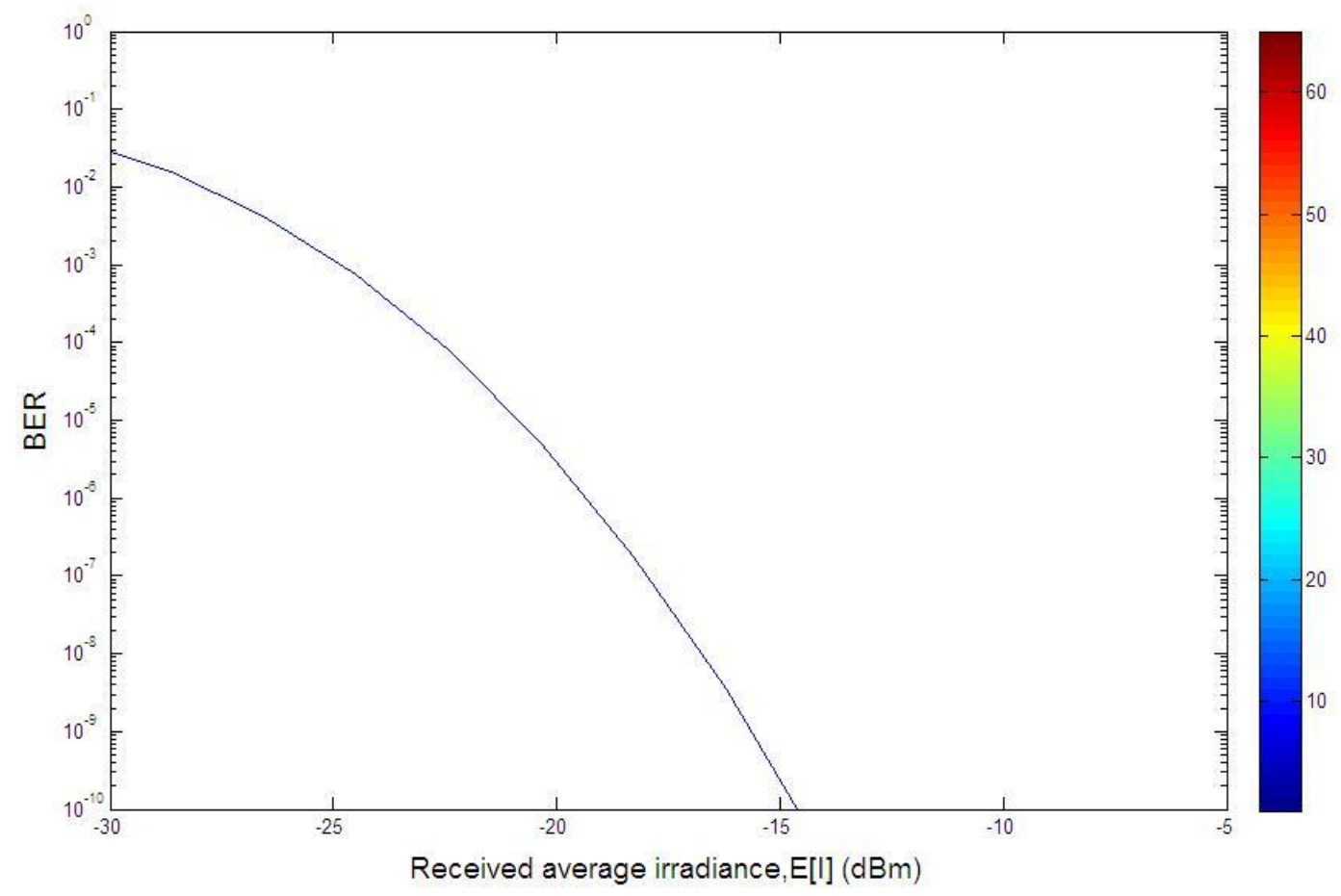

Fig.12: Received average irradiance, E [I] (dBm) VS BER. 


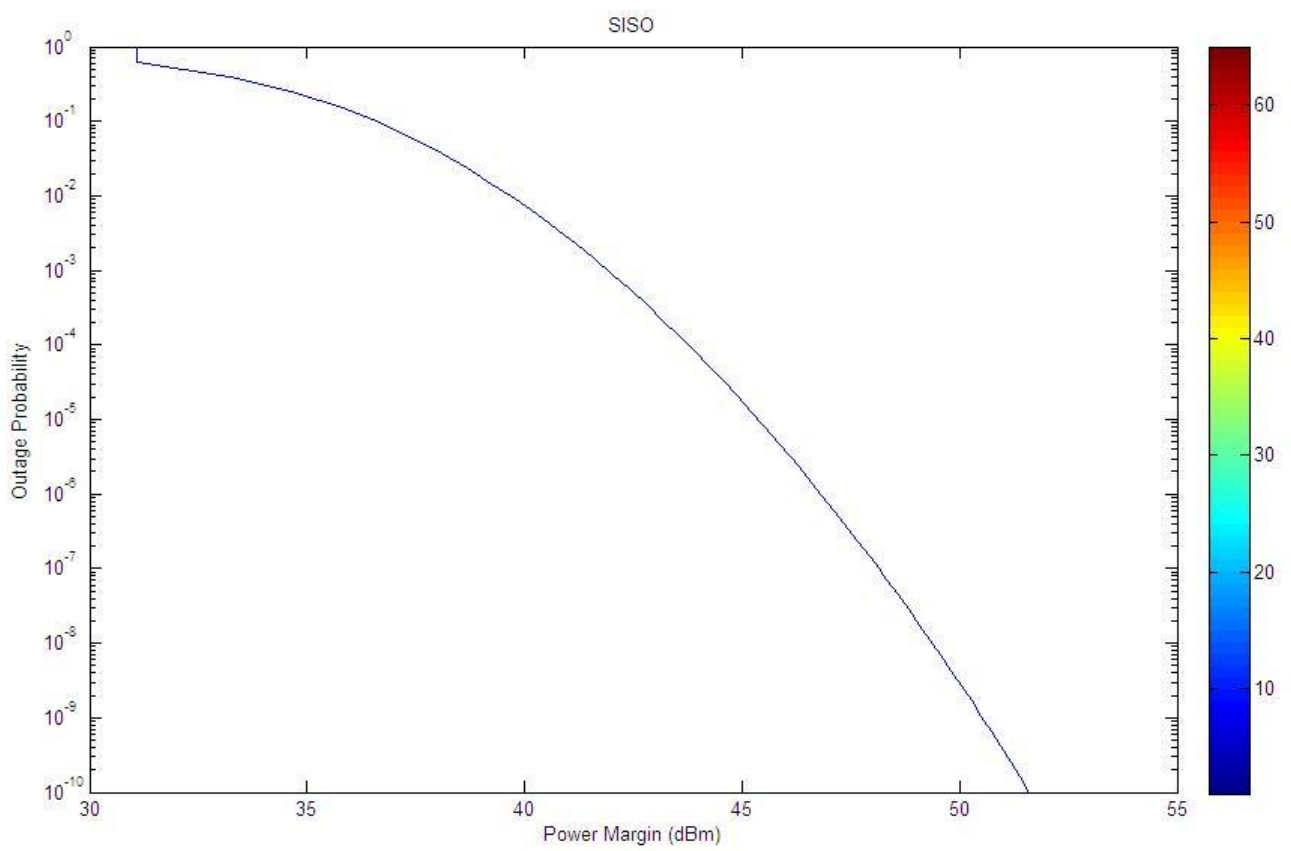

Fig.13: Outage probability against the power margin for a log-normal turbulent atmospheric channel for $\sigma_{1}^{2}=0.5$

IX. Analysis Laser transfer in turbulent atmosphere, Spot scale, offset angle and light intensity fluctuations are related to transmission distance and the turbulence intensity of the relations.
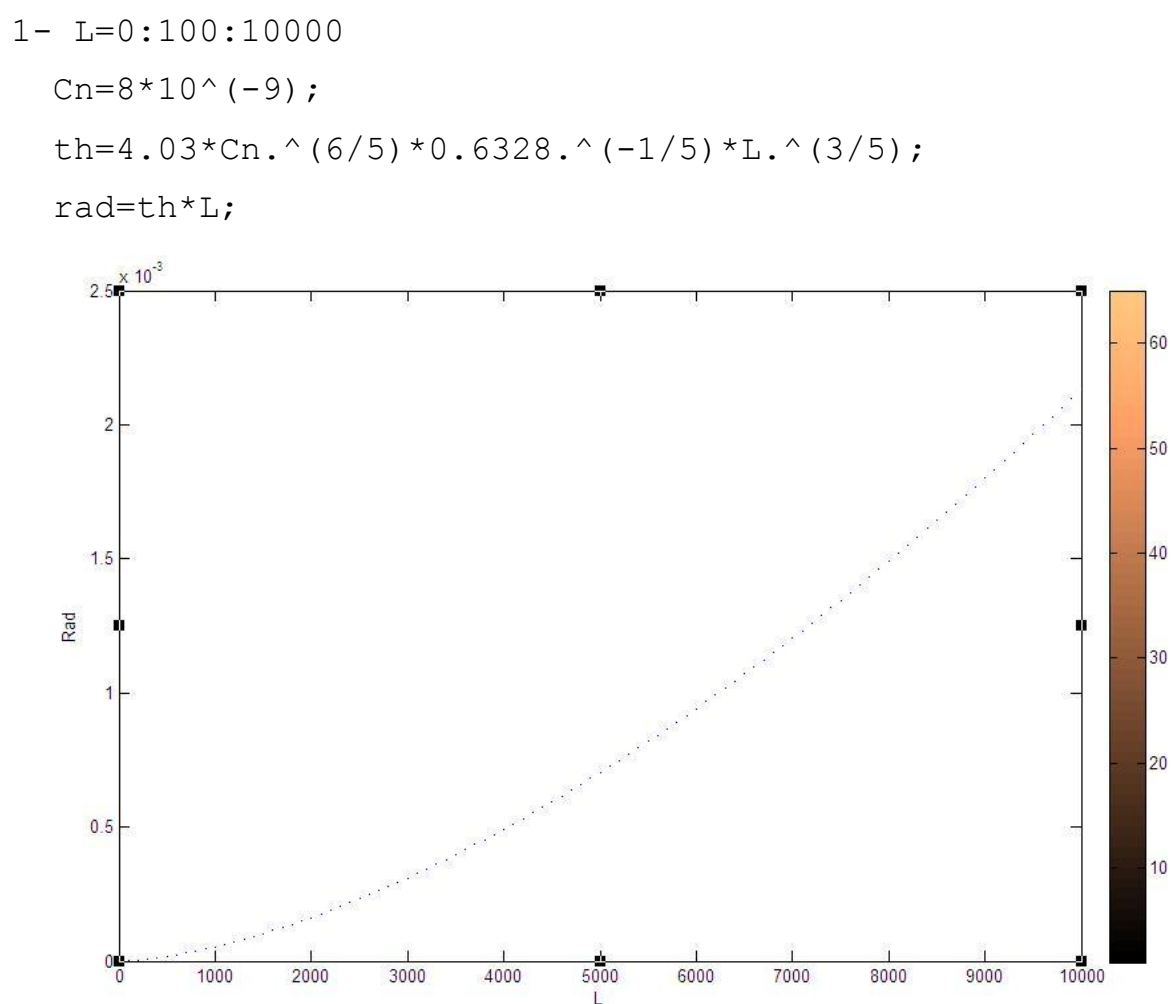

Fig.14: Lfso vs Rad (beam divergence of transmitter ). when $\mathrm{Cn}=8 \star 10^{\wedge}(-9)$. 

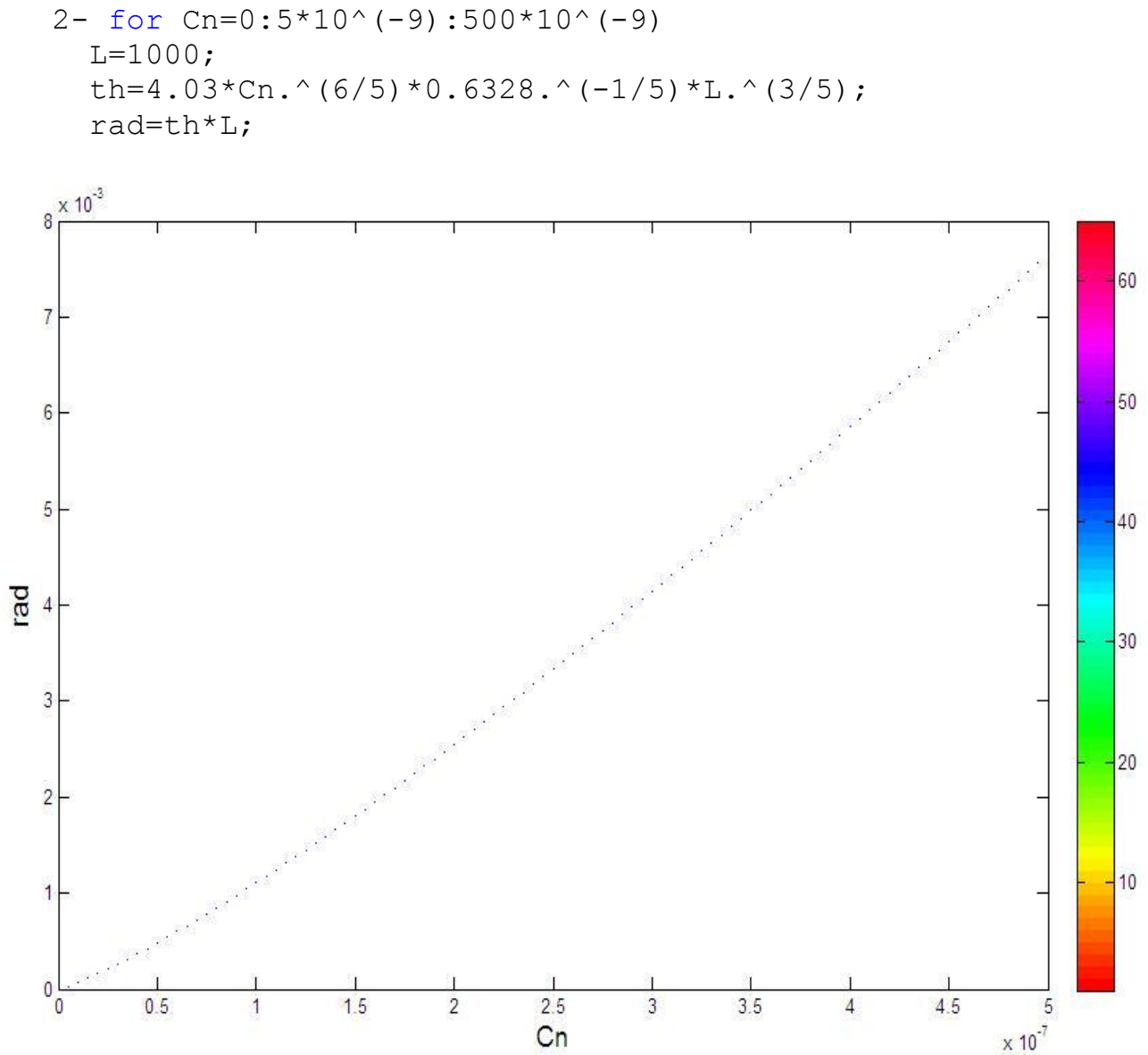

Fig.15 : Refractive index strucure vs beam divergence .
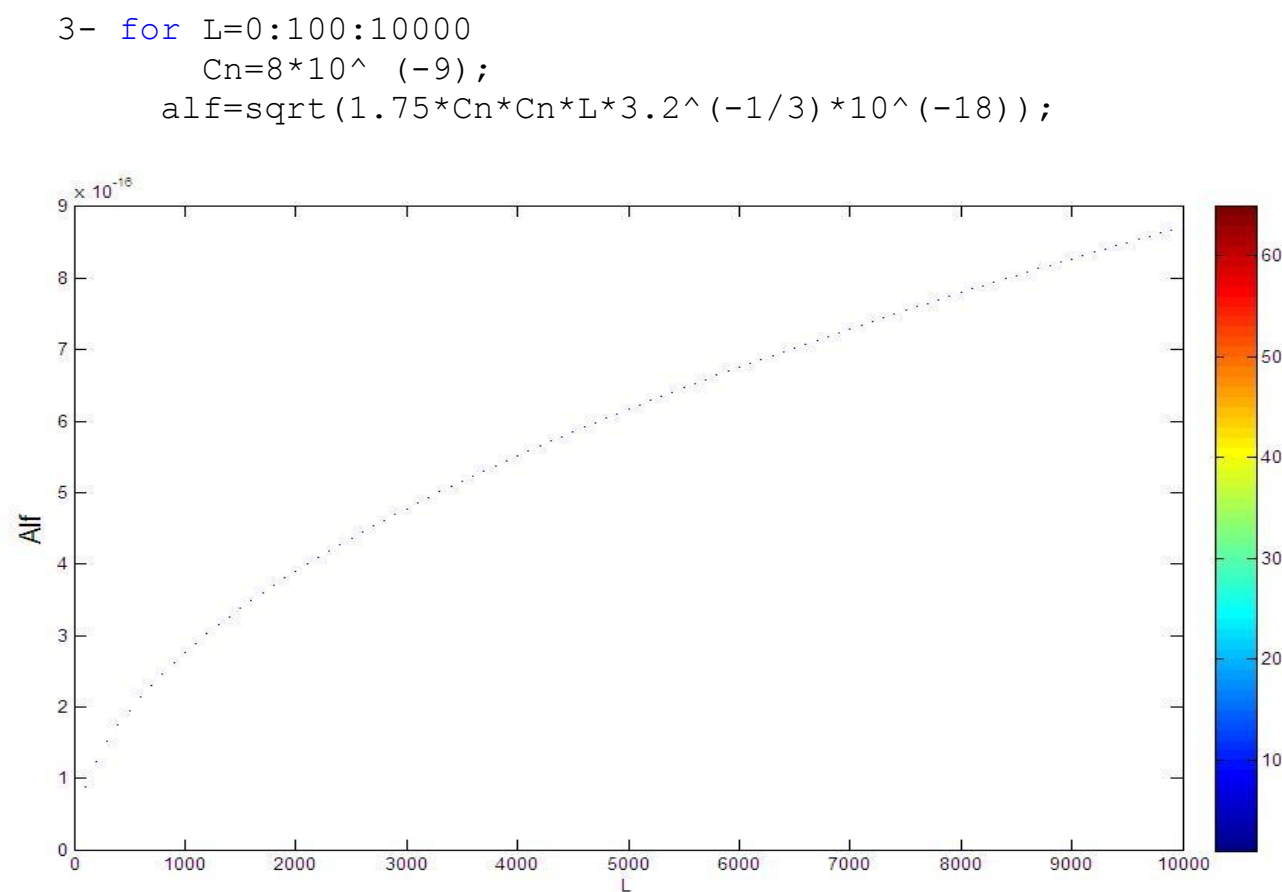

Fig.16: Lfso vs Attenuation (Alfa). 
4- for $\mathrm{Cn}=0: 5 * 10^{\wedge}(-9): 500 * 10^{\wedge}(-9)$

$\mathrm{L}=1000$;

alf $=\operatorname{sqrt}\left(1 \cdot 75^{*} \mathrm{Cn}{ }^{\star} \mathrm{Cn}{ }^{*} \mathrm{~L}^{\star} 3 \cdot 2^{\wedge}(-1 / 3) * 10^{\wedge}(-18)\right)$;

plot (Cn, alf, '- ')

hold on

end

xlabel ('cn')

ylabel ('alf')

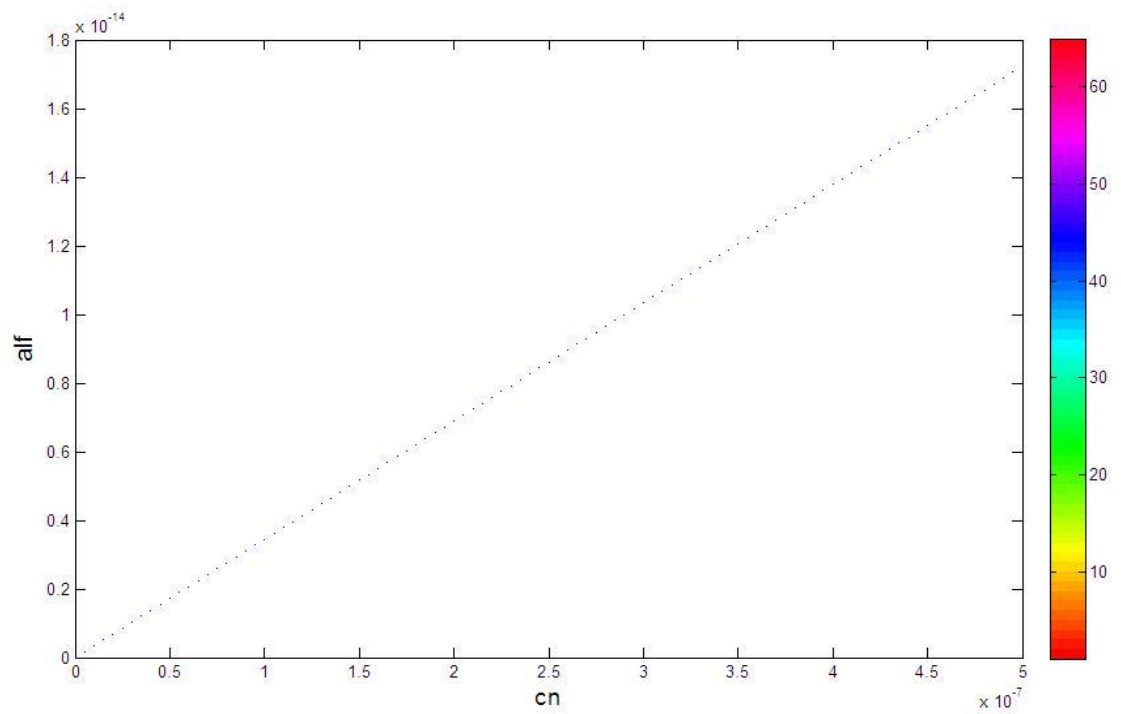

Fig.17: Refractive index structure vs Alfa.

$5-\mathrm{B}=0.49$

for $L=0: 10: 10000$

$\mathrm{Cn}=8 * 10^{\wedge}(-9)$;

$\mathrm{I}=\mathrm{B} *(2 * \mathrm{pi} / 0.6328) \cdot{ }^{\wedge}(7 / 6) * \mathrm{~L} \cdot{ }^{\wedge}(11) * \mathrm{Cn} \cdot{ }^{\wedge} 2 * 10^{\wedge}(-18) ;$ plot $(L, I, '-')$

hold on

end

xlabel ('L')

ylabel ('intensity')

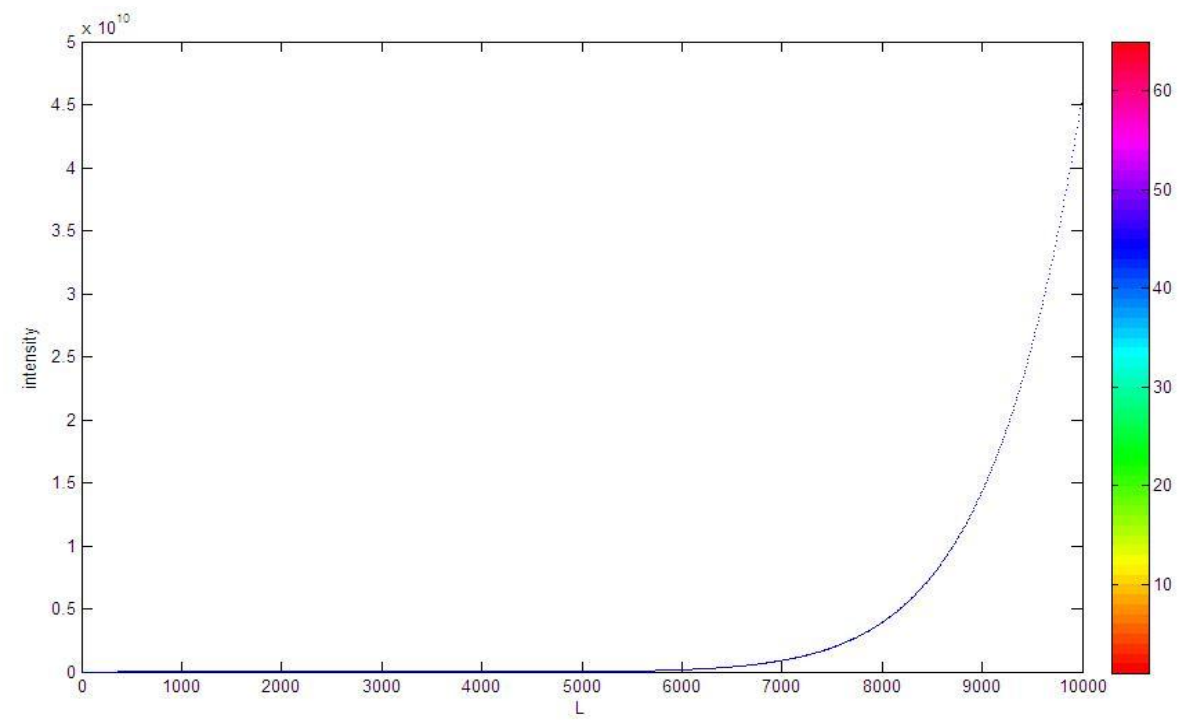

Fig.18: Lfso vs Trubluence intensity. 

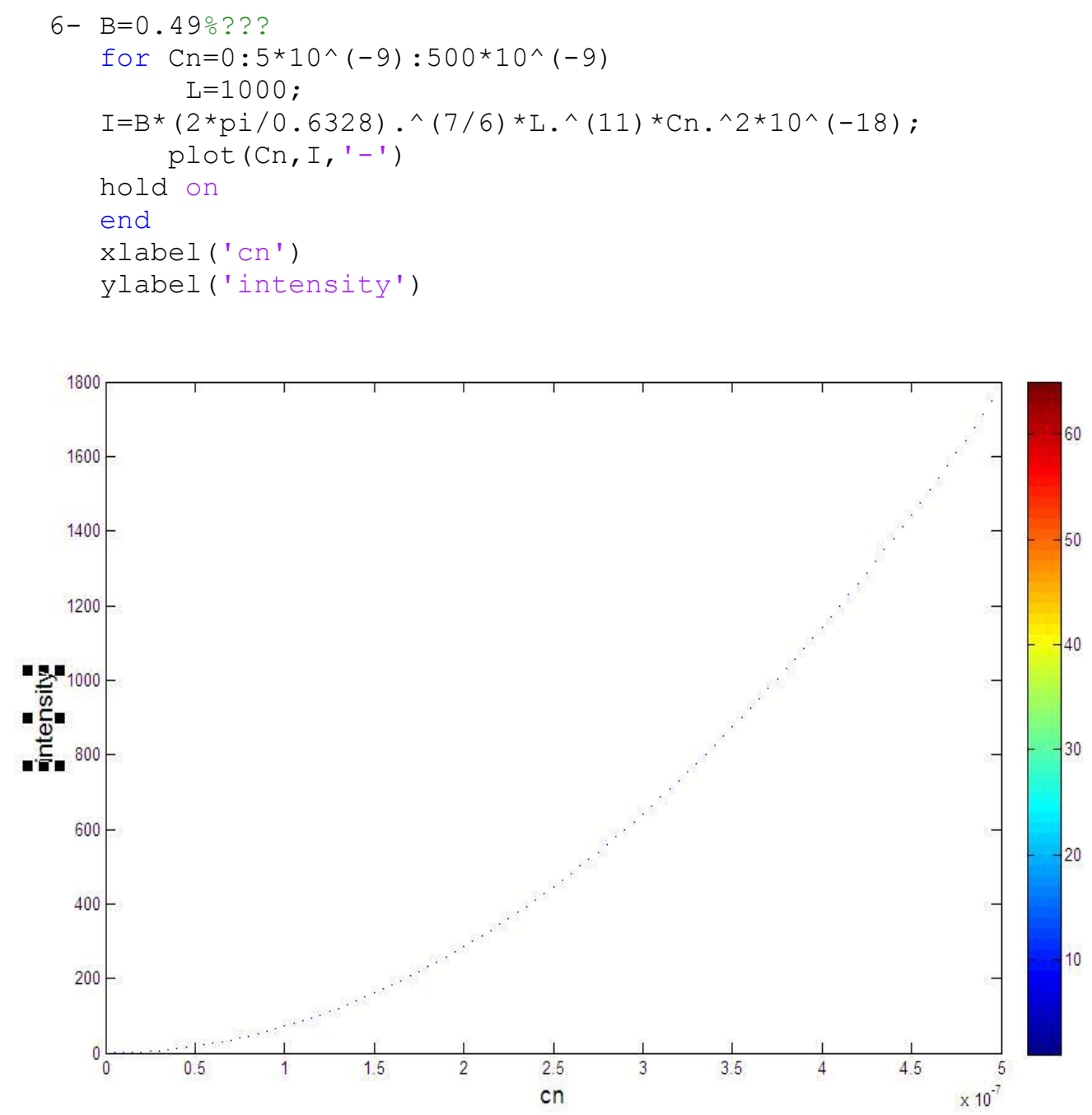

Fig.19: Refractive index structure vs Trublence intensity.

\section{Conslusion}

We analysed A hybrid fibre and FSO WDM network and the effects of turbulence-accentuated interchannel crosstalk, it could be seen that DPPM systems required lower optical power copmared to OOK systems. It can be deduced from this analysis tha tinterchannel crosstalk,turbulence-induced scintillation, and ASE noises are dominant causesof system degradation, especially in the upstream transmission, causing the BER to increase by several orders of magnitude. 


\section{References}

1.Mukherjee, B.:'WDM optical communication networks :progress and challenges'. IEEE J. Selected Areas in Commun., 2000, 18,(10),pp.1810-1824 2.Ciaramella,E.,Arimoto,Y.,Contestabile,G.,Presi,M.,D'Errico,A.,Guarino,V., Matsumoto,M.:'1.28 tera bit/s (32x40Gbit/s) wdm transmission system for free space optical communications'. IEEEJ.Selected Areas in Commun., 2009, 27,(9), pp.1639-1645.

3.Forbes, M.,Gourlay,J.,Desmulliez,M.:'Optically interconnected electronic chips:a tutorial and review of the technology'. J.Electron.\& Commun.Eng., 2001, 13,(5), pp.221-232.

4.Forin,D.M.,Beleffi,G.M.T.,Curti,F.,Corsi,N.,DeSanctis,V.,Sacchieri,V.,Teixe ira,A.J.L.,etal.:'On field test of a Wavelength Division Multiplexing Free Space Optics transmission at very high bit rates'. 9thInt.Conf.Telecommun. 2007, pp.77-80.

5.Chang-Hee,L.,Sorin,W.V.,Byoung-Yoon,K.:'Fiber to the Home Using a PON Infrastructure'. J.Lightw.Technol., 2006, 24,(12),pp.4568-4583

6.Ramaswami,R.,Sivarajan,K.N.,Sasaki,G.H. Optical Networks:A Practical Perspective. 3rded.Boston:Morgan Kaufmann Publishers;2010.

7.Pei-Lin,C.,Shenq-Tsong,C.,Shuen-Te,J.,Shu-Chuan,L.,Han-Hsuan,L.,Ho-Lin, T.,Po-Hsuan,H.,etal.:'Demonstration of 16 channels $10 \mathrm{~Gb} / \mathrm{sWDM}$ free space transmission over2.16 km'. Digest of the IEEE / LEOS Summer Topical Meetings 2008,pp.235-236.

8.Aladeloba,A.O.,Phillips,A.J.,Woolfson,M.S.:'Improved bit error rate evaluation

for optically pre-amplified free-space optical communication systems in turbulent atmosphere'. IET Optoelectron., 2012, 6,(1),pp.26-33.

9.Qianling,C.,Brandt-Pearce,M.,Wilson,S.G.:'Optically Amplified Wireless Infrared MISO Systems'. IEEE Global Telecommun.Conf., 2007,pp.4505-4510 10.Barry,J.R. Wireless Infrared Communications.Bost on: Kluwer Academic Publishers;19941994.

11.Kedar,D.,Arnon,S.:'Urban optical wireless communication networks: the main challenges and possible solutions'. IEEE Commun.Mag., 2004, 42,(5),pp.S2-S7. 
12.Kahn, J. M., Barry,J. R.:'Wireless infrared communications'. Proc .IEEE, 1997, 85, (2),pp.265-298.

13. W. O. Popoola, ZGhassemlooy, J. I. H. Allen, E. Leitgeb and S. Gao, Freespace optical communication employing subcarrier modulation and spatial diversity in atmospheric turbulence channel, IET Optoelectronics, 2, 16-23, 2008.

14. H. Hemmati, Interplanetary laser communications, Optics and Photonics News, 18, 22-27, 2007.

15. Monroy,I.T.,Tangdiongga,E. Crosstalk in WDM Communication Networks. Norwell, Massachusetts, USA,: Kluwer Academic Publishers;2002.

16.Ghassemlooy, Z.,Popoola, W.,Rajbhandari, S. Optical Wireless Communications System and Channel Modelling with MATLAB.1sted.London:CRC Press ;2013.

17. J. G. Proakis, Digital Communications, New York: McGraw-Hill, 2004.

18. A.O.Aladeloba, A.J.Phillips, and M.S.Woolfson, "DPPM FSO communication systemsimpaired by turbulence, pointing error and ASE noise," in $14^{\text {th }}$ Int.Conf.onTransparent Optical Networks (ICTON), Coventry, $\mathrm{UK}, 2012$.

18. WDM FSO Network With Turbulence Accentuated Interchannel Crosstalk Abisayo O. Aladeloba, Malcolm S. Woolfson, and Andrew J. Phillips. 19. Y. Dikmelik and F. M. Davidson, "Fiber-coupling efficiency for free-space optical communication through atmospheric turbulence," Appl.Opt.,vol.44,pp.49464952,Aug.2005.

19. M. Abtahi, P. Lemieux, W. Mathlouthi, and L . A. Rusch, "Suppression of turbulence-induced scintillation in free-space optical communication systems using saturated optical amplifiers," J.LightwaveTechnol.,vol.24,pp.4966-4973, 2006.

20.Gianordoli ,S. , Rasztovits-Wiech ,M., Stadler, A., Grabenhorst, R.:' Next generation PON'. Elektrotechnik und Informations technik, 2006, 123,(3),pp.78-82.

21.Kahn,J.M.,Barry,J.R.:'Wireless infrared communications'. Proc. IEEE, 1997, 85, (2),pp.265-298. 
22.Ntogari, G., Kamalakis, T.,Sphicopoulos, T. :'Analysis of Indoor MultipleInput Multiple-Output Coherent Optical Wireless Systems'. J.Lightw.Technol., 2012, 30, (3),pp.317-324

23.Matsuo,R.,Matsuo,M.,Ohtsuki,T.,Udagawa,T.,Sasase,I.:'Performance analysis of indoor infrared wireless systems using OOK CDMA on diffuse channels'. IEEE Pacific Rim Conf.on Commun.,Comput.andSignal Processing 1999,pp.30-33

24 .Ohtsuki,T.:'Performance analysis of indoor infrared wireless systems using PPM CDMA'. Electronics and Commun.in Japan 2002, 85,(1),pp.1-10.

25.Ke,W.,Nirmalathas,A.,Lim,C.,Skafidas,E.:' 4x12.5 Gb/s WDM Optical Wireless Communication System for Indoor Applications'. J.Lightw.Technol., 2011, 29,(13),pp.1988-1996.

26.Elgala, H. , Mesleh, R ., Haas, H.: 'Indoor optical wireless communication: potential and state-of-the-art'. IEEE Commun.Mag.,2011, 49, (9), pp. 56-62

27.Komine,T., Nakagawa, M. :' Fundamental analysis for visible-light

Communication System using LED lights'. IEEE Trans.Consum.Electron., 2004, 50,(1),pp.100-107.

28. J. Prat, Next-Generation FTTH Passive Optical Networks: Research Towards Unlimited Bandwidth Access. Springer 2008.

29. B. B. Yousif, E. E. Elsayed, and M. M. Alzalabani, “Atmospheric turbulence mitigation using spatial mode multiplexing and modified pulse position modulation in hybrid RF/FSO orbital-angular-momentum multiplexed based on MIMO wireless communications system," Opt. Commun., vol. 436, pp. 197-208, 2019, doi: 10.1016/j.optcom.2018.12.034.

30. A. M. Mbah, J. G. Walker, and A. J. Phillips, "Outage probability of WDM free-space optical systems affected by turbulence-accentuated interchannel crosstalk," IET Optoelectron., vol. 11, no. 3, pp. 91-97, 2017, doi: 10.1049/ietopt.2016.0057.

31. B. B. Yousif and E. E. Elsayed, "Performance Enhancement of an OrbitalAngular-Momentum-Multiplexed Free-Space Optical Link under Atmospheric Turbulence Effects Using Spatial-Mode Multiplexing and Hybrid Diversity Based on Adaptive MIMO Equalization,” IEEE Access, vol. 7, pp. 8440184412, 2019, doi: 10.1109/ACCESS.2019.2924531.

32. E. E. Elsayed and B. B. Yousif, "Performance enhancement of hybrid diversity for M-ary modified pulse-position modulation and spatial modulation of MIMO-FSO systems under the atmospheric turbulence effects with geometric spreading," Opt. Quantum Electron., vol. 52, no. 12, 2020, doi: 10.1007/s11082-020-02612-1.

33. Ebrahim E. Elsayed, Bedir B. Yousif, and Mahmoud M. Alzalabani, "Performance enhancement of the power penalty in DWDM FSO 
communication using DPPM and OOK modulation", Optical and Quantum Electronics, vol. 50 (7), pp. 282, (26 June 2018).

34. Ansari, N., Zhang, J.: 'Media access control and resource allocation for next generation passive optical networks' (Springer, 2013)

35. Ebrahim E. Elsayed and Bedir B. Yousif, "Performance enhancement of the average spectral efficiency using an aperture averaging and spatial-coherence diversity based on the modified-PPM modulation for MISO FSO links", Optics Communications, vol. 463, pp. 125463, (15 May 2020).

\section{Compliance with ethical standards}

Conflict of interest: The author declares that there is no conflict of interest regarding the manuscript. The author is responsible for the content and writing of this article. The author declares that he has no known competing financial interests or personal relationships that could have appeared to influence the work reported in this paper. 


\section{Figures}
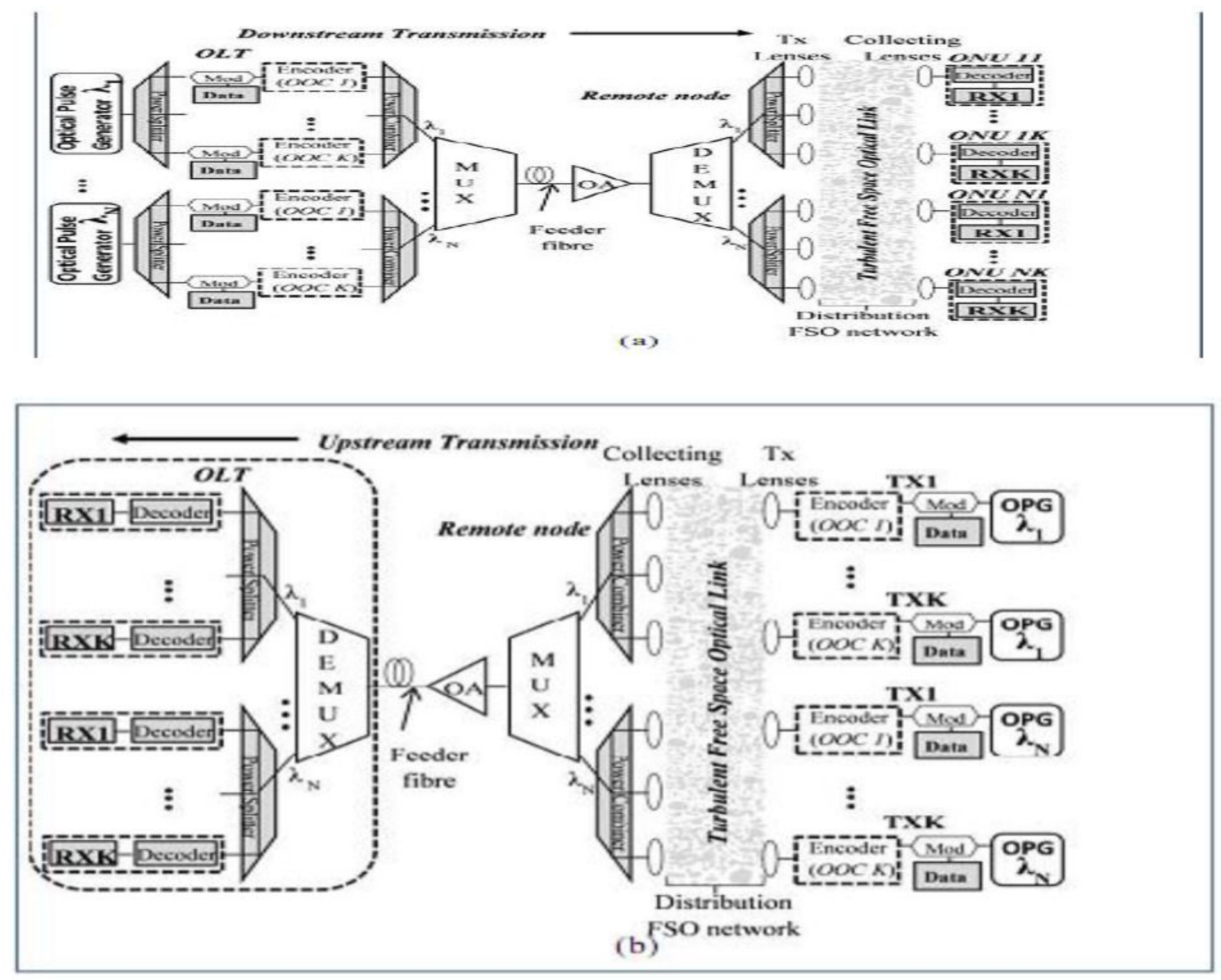

Figure 1

Hybrid WDM and OCDMA Network with Optical fibre and FSO links: (a) Downstream network diagram and (b) Upstream network diagram 


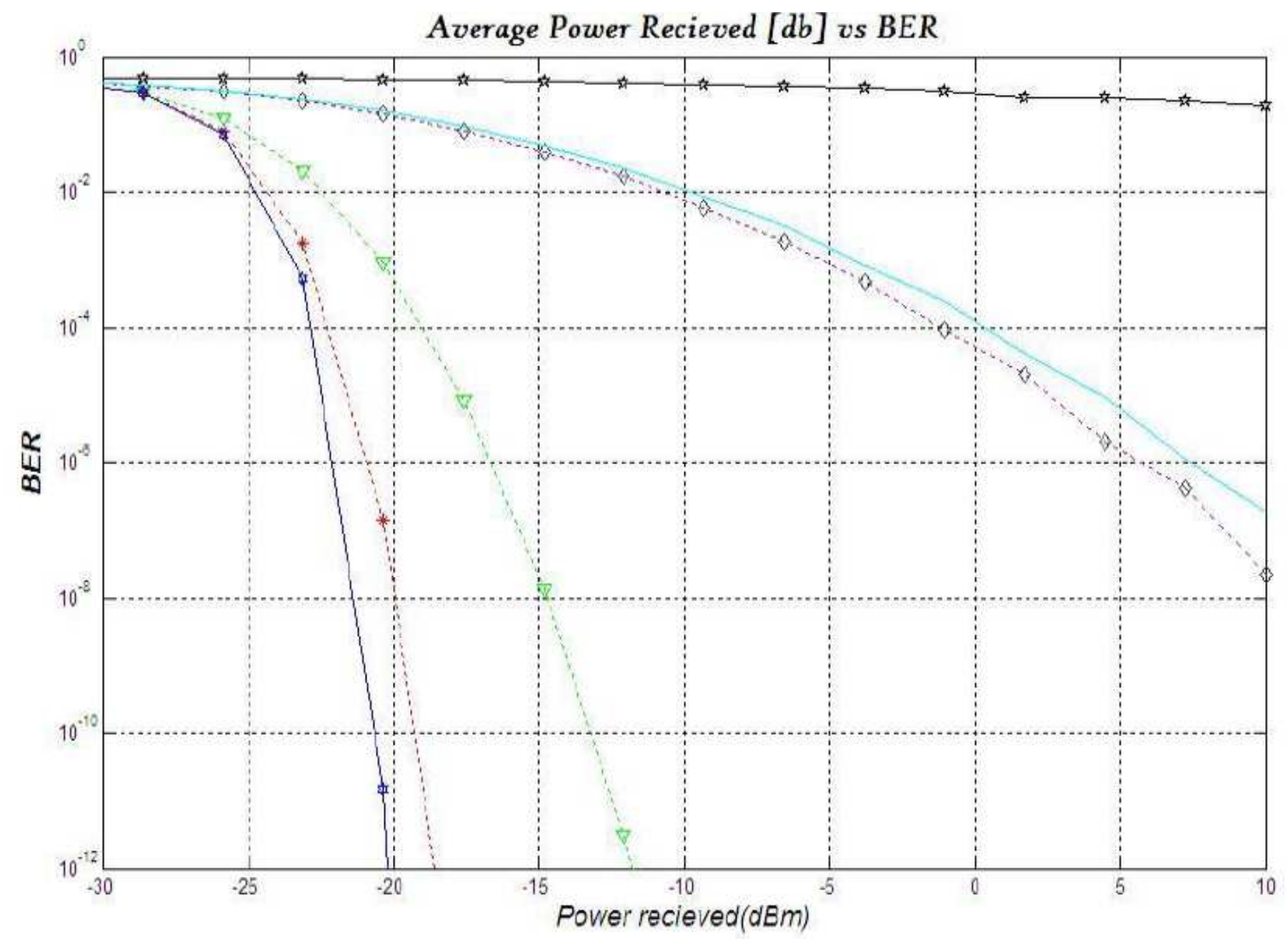

Figure 2

Power received vs BER in upstream transmission. 


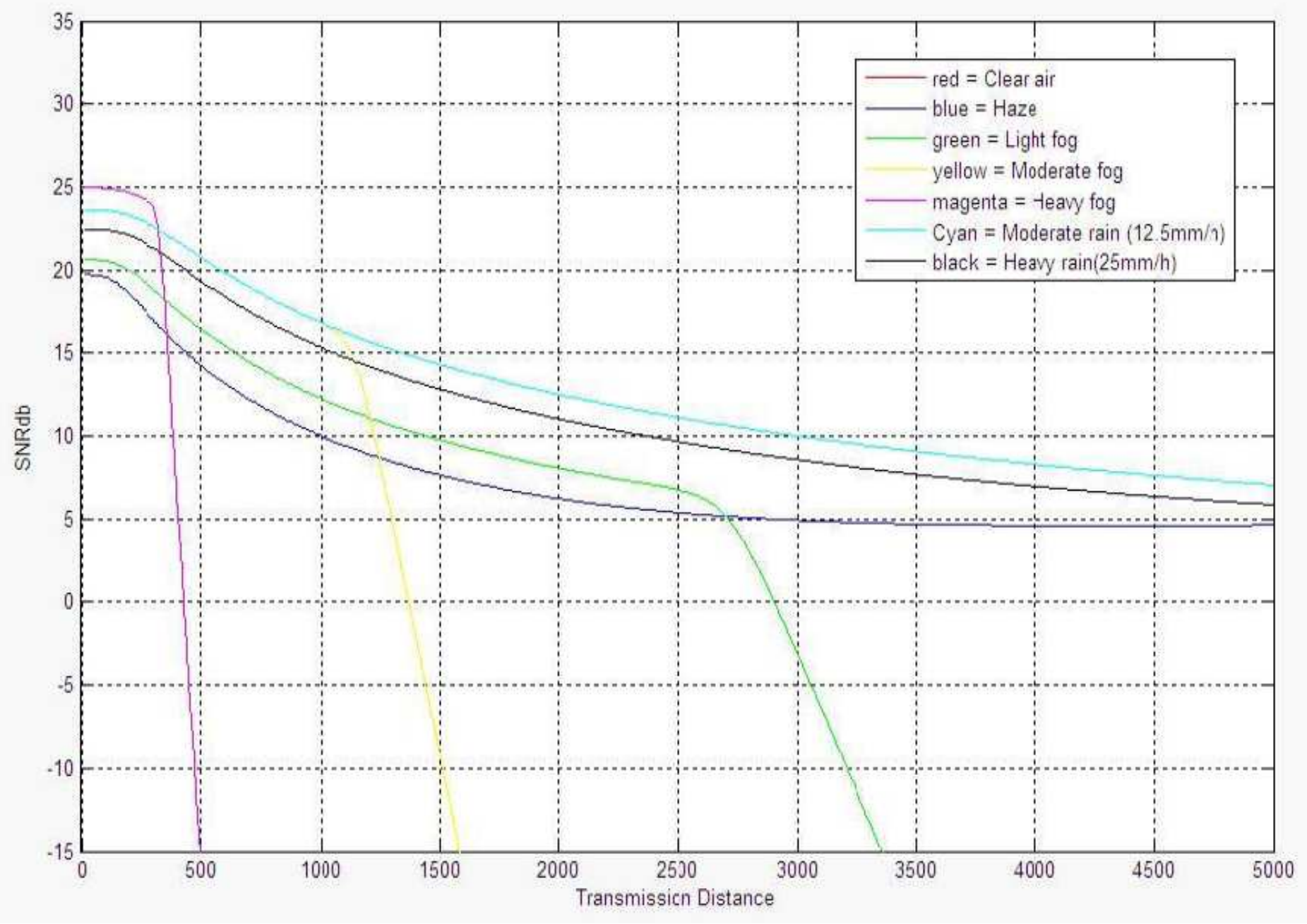

Figure 3

Transmission distance L_fso $=5 \mathrm{~km}$ vs Signal to-Noise ratio in upstream transmission 


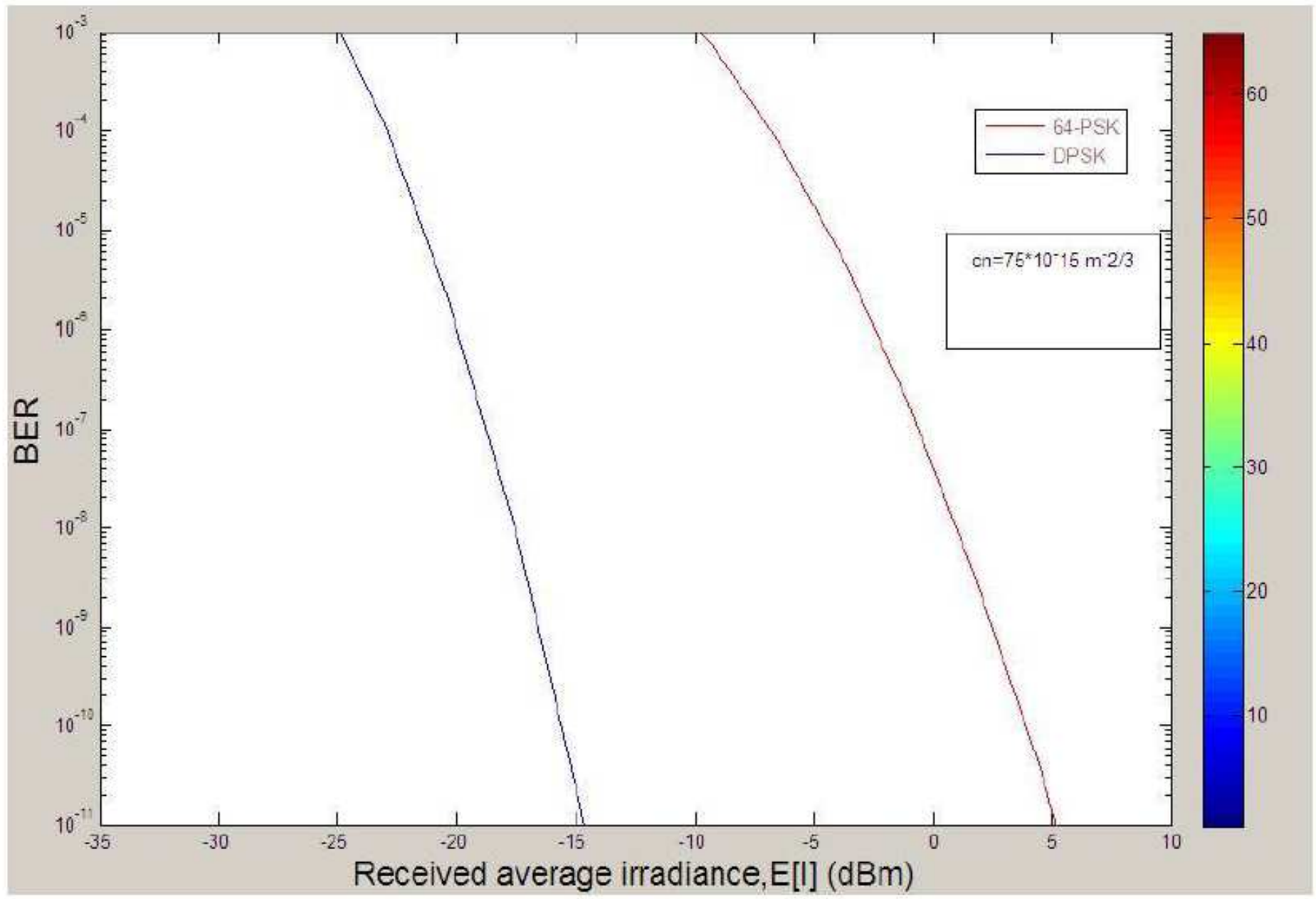

Figure 4

Received average irradiance [I] vs BER in downstream transmission. 


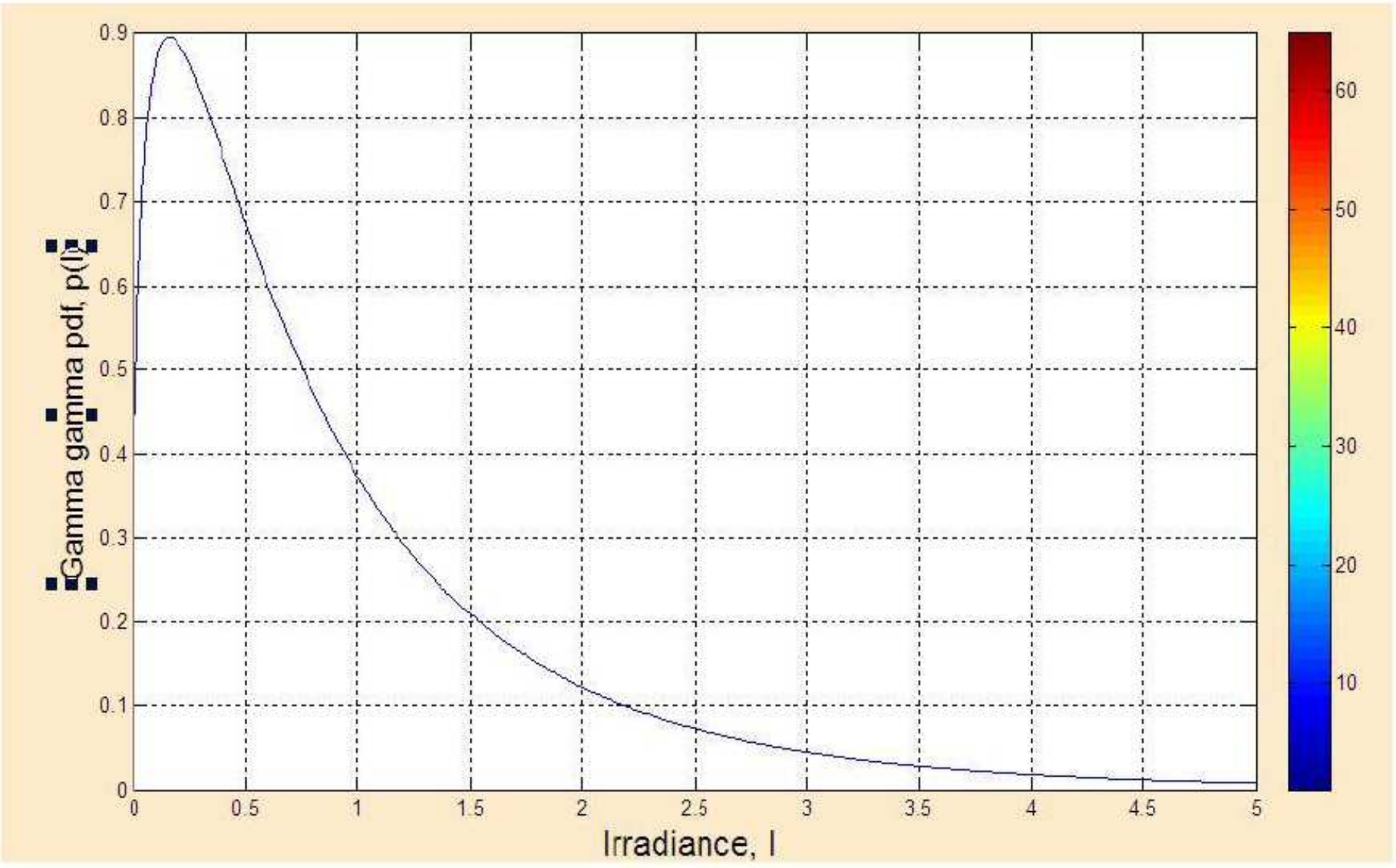

Figure 5

Please see the Manuscript PDF file for the complete figure caption. 


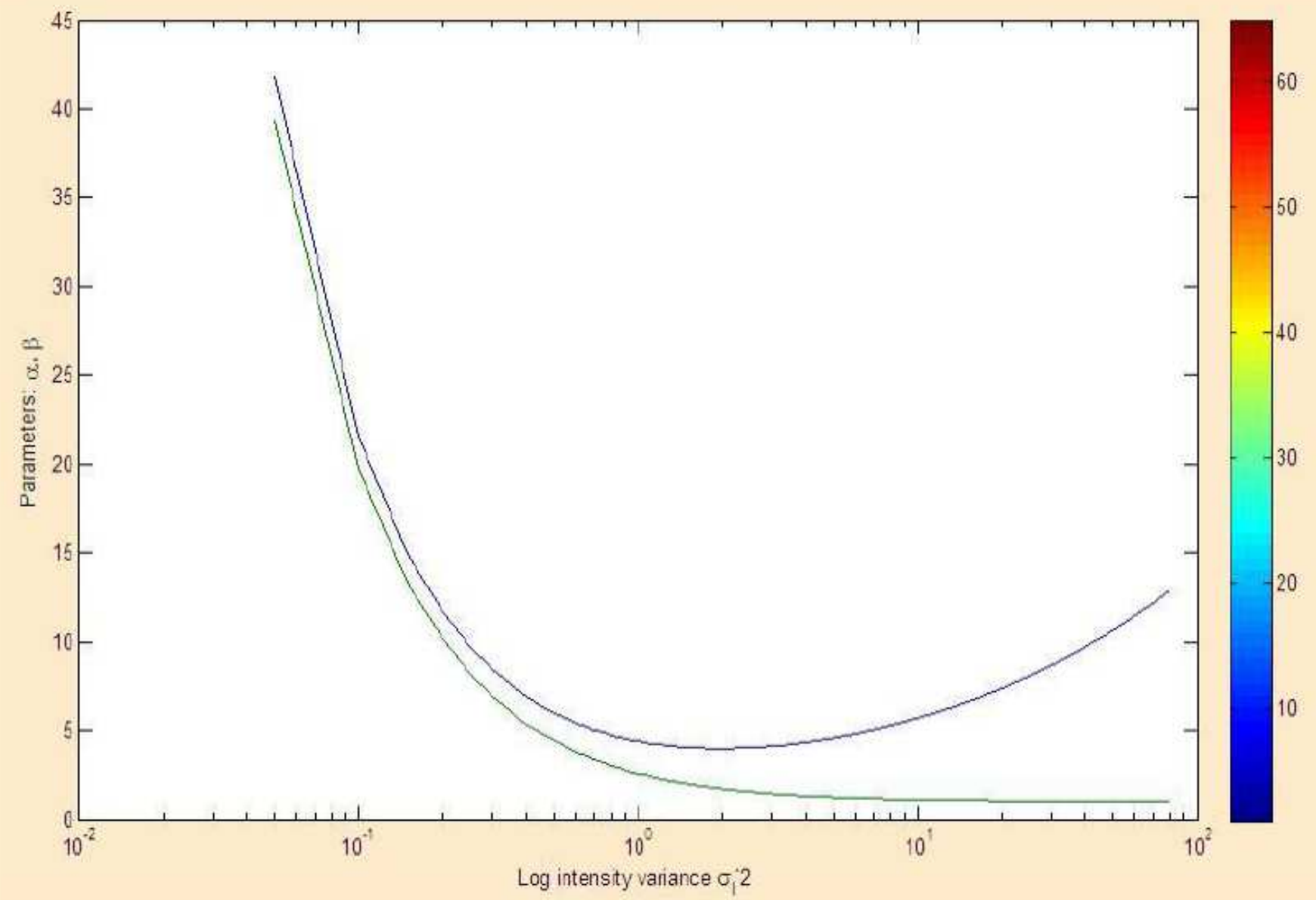

Figure 6

Values of $a$ and $\beta$ under different turbulence regimes: weak, moderate to strong and saturation. 


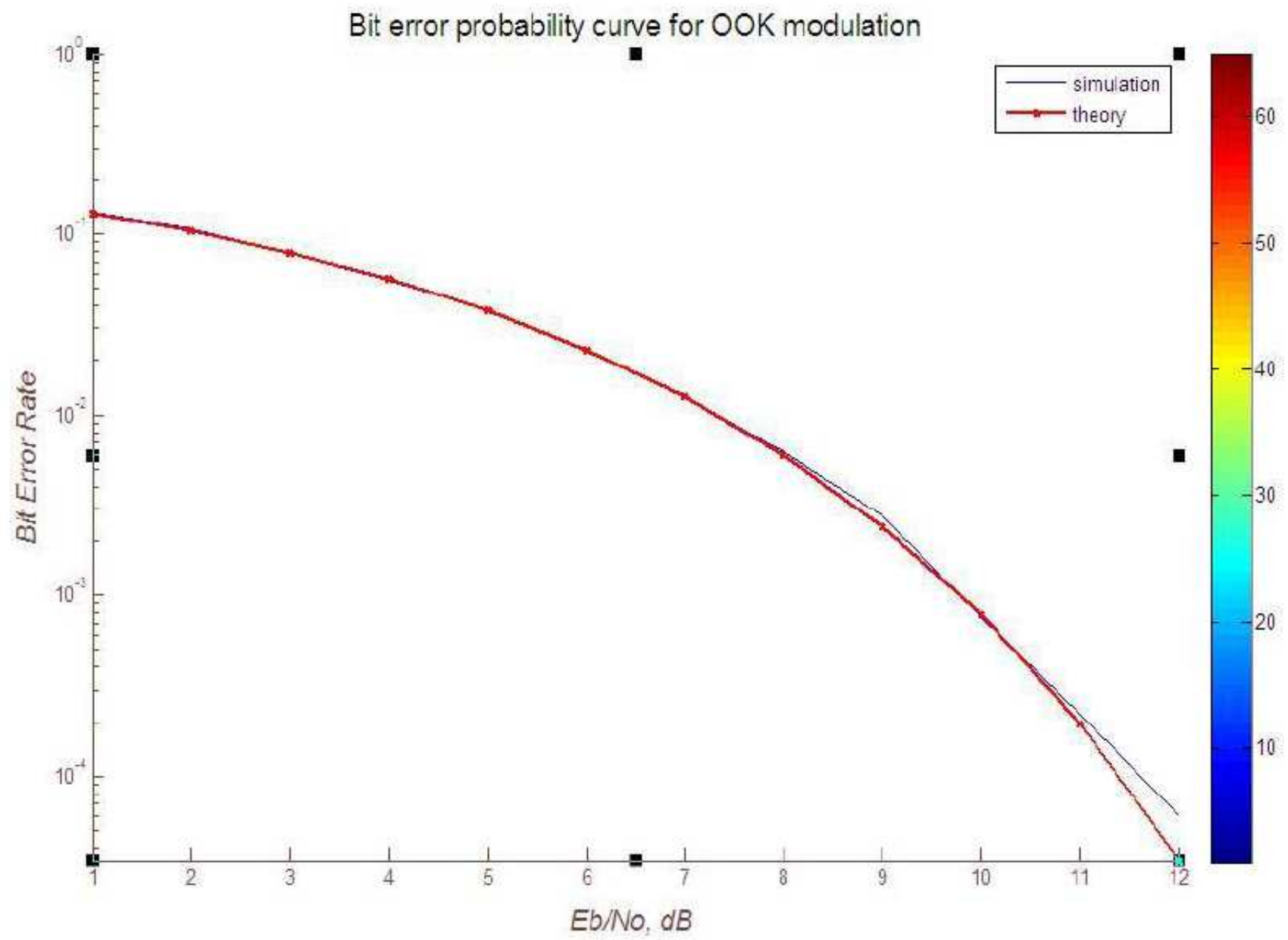

Figure 7

Bit error probability curve for OOK modulation. 


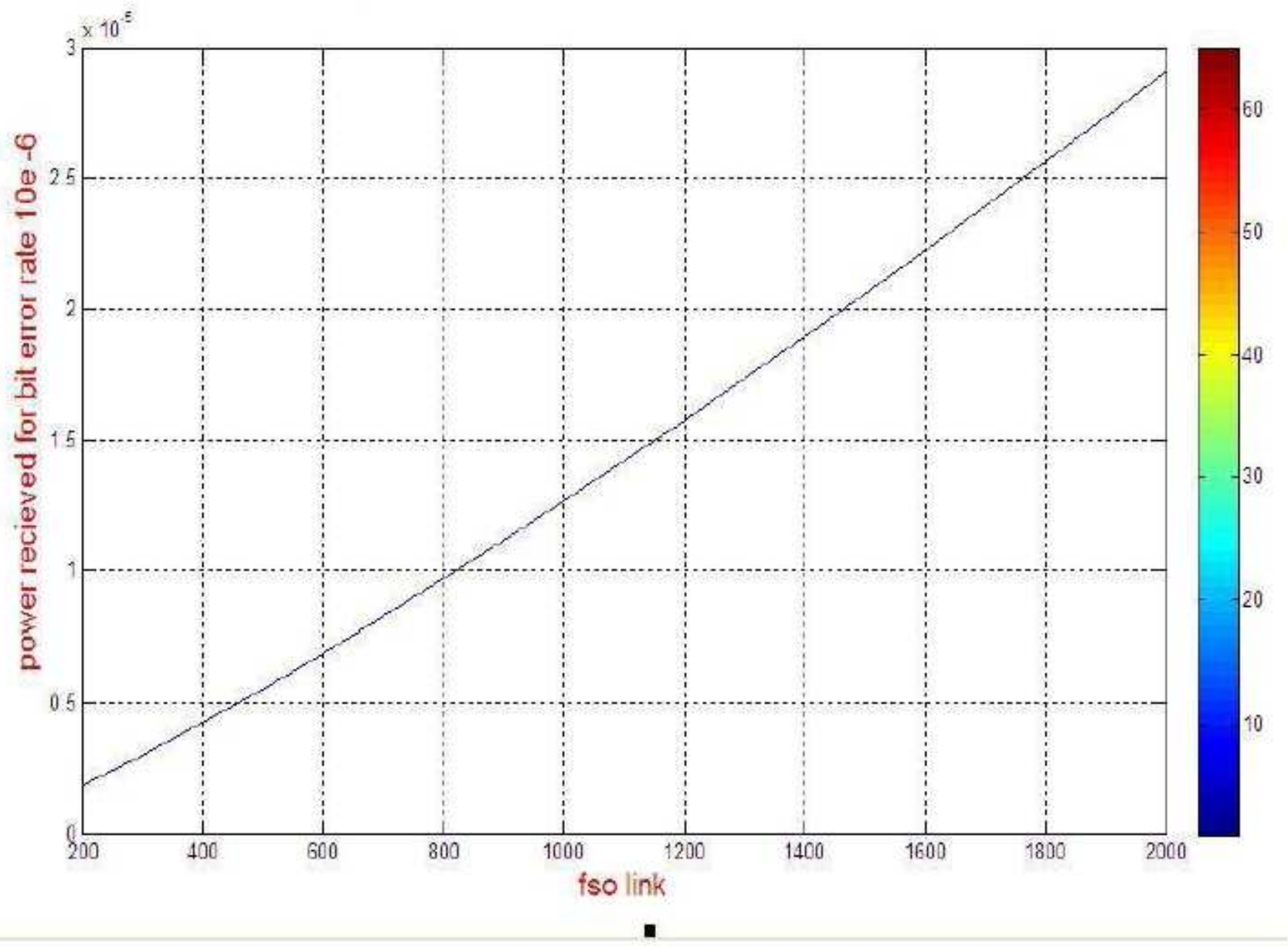

Figure 8

Please see the Manuscript PDF file for the complete figure caption. 


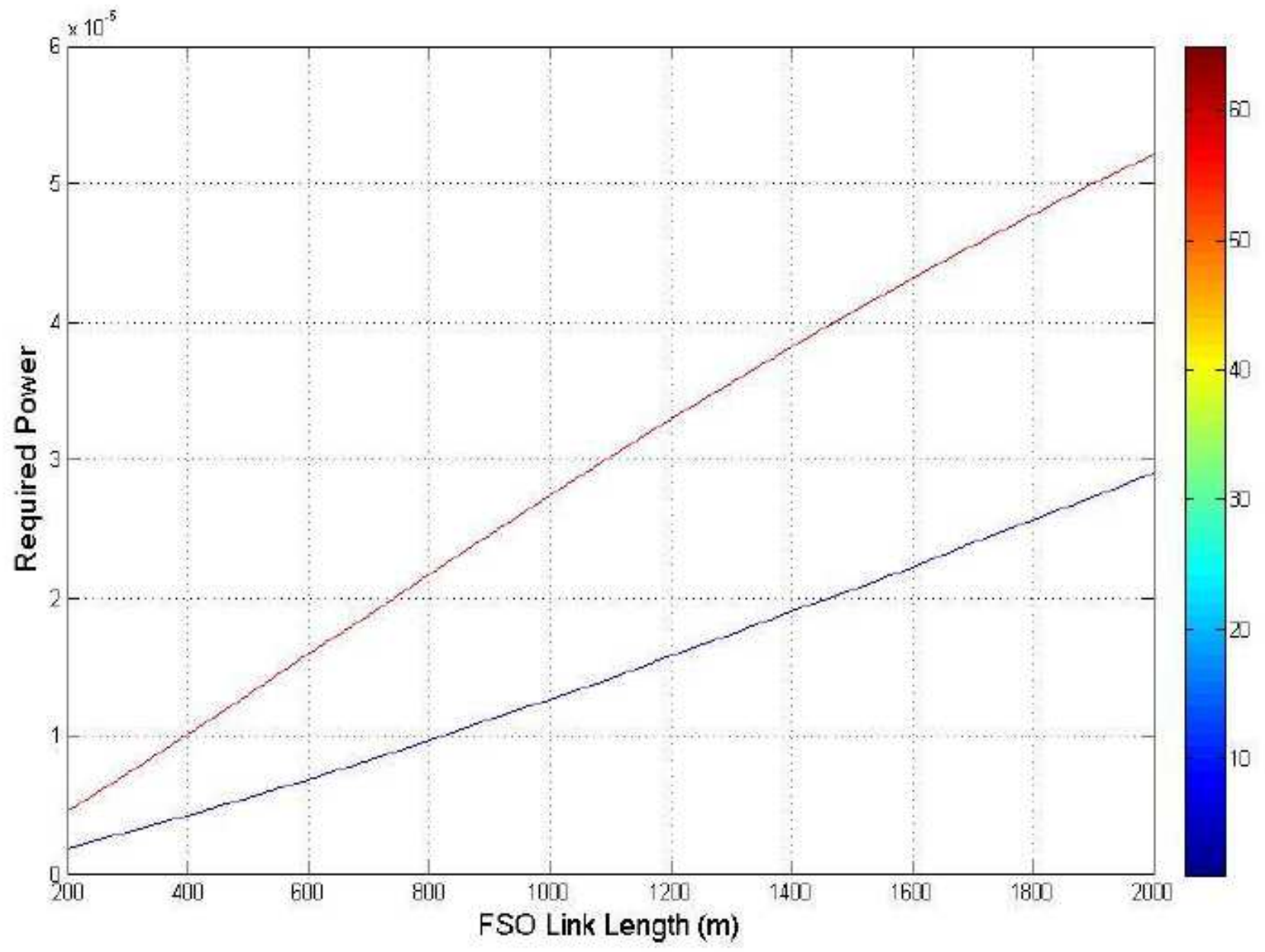

Figure 9

Please see the Manuscript PDF file for the complete figure caption. 


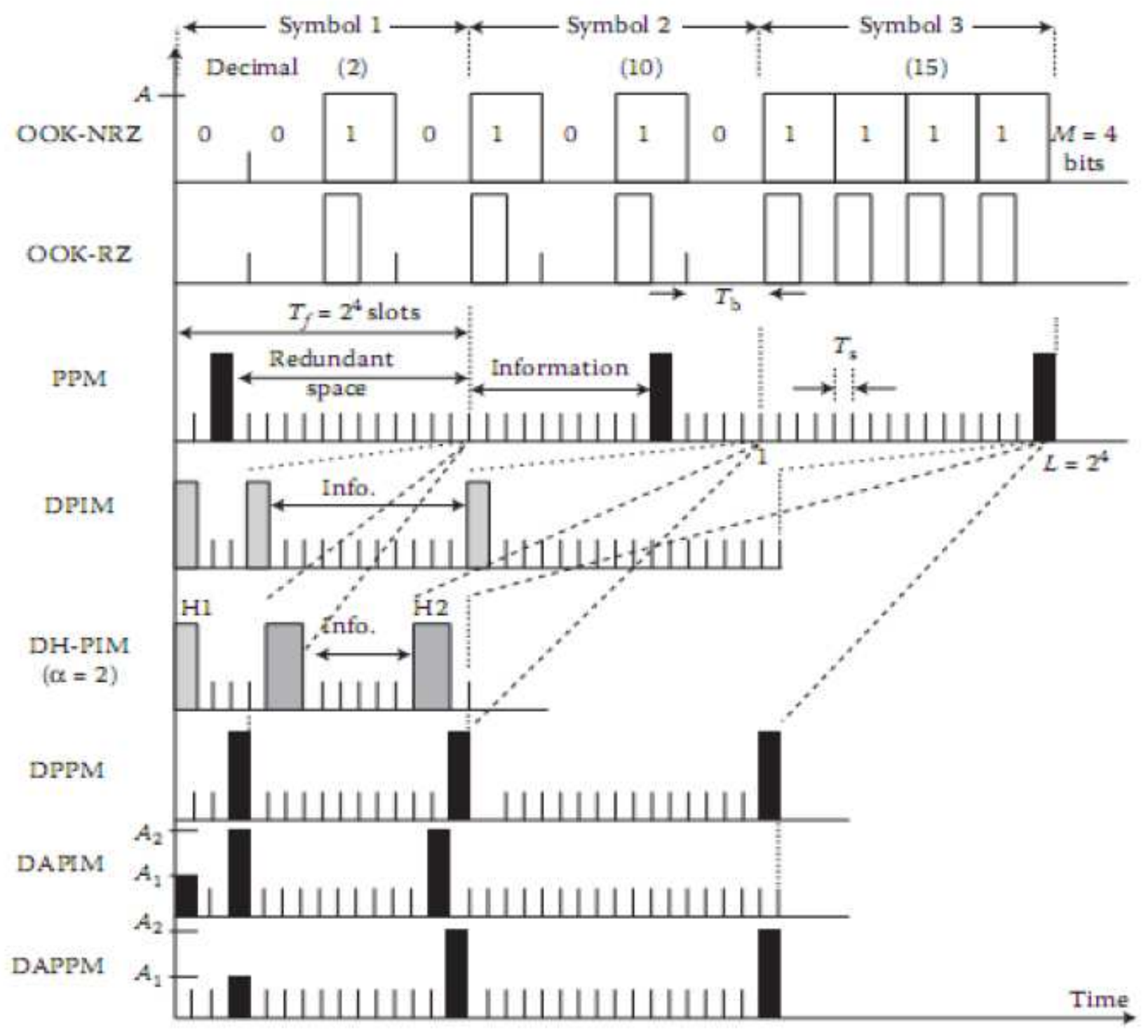

Figure 10

Time waveforms for OOK, PPM, DPI, DH-PIM, DPPM, DAPIM and DAPPM signals. 


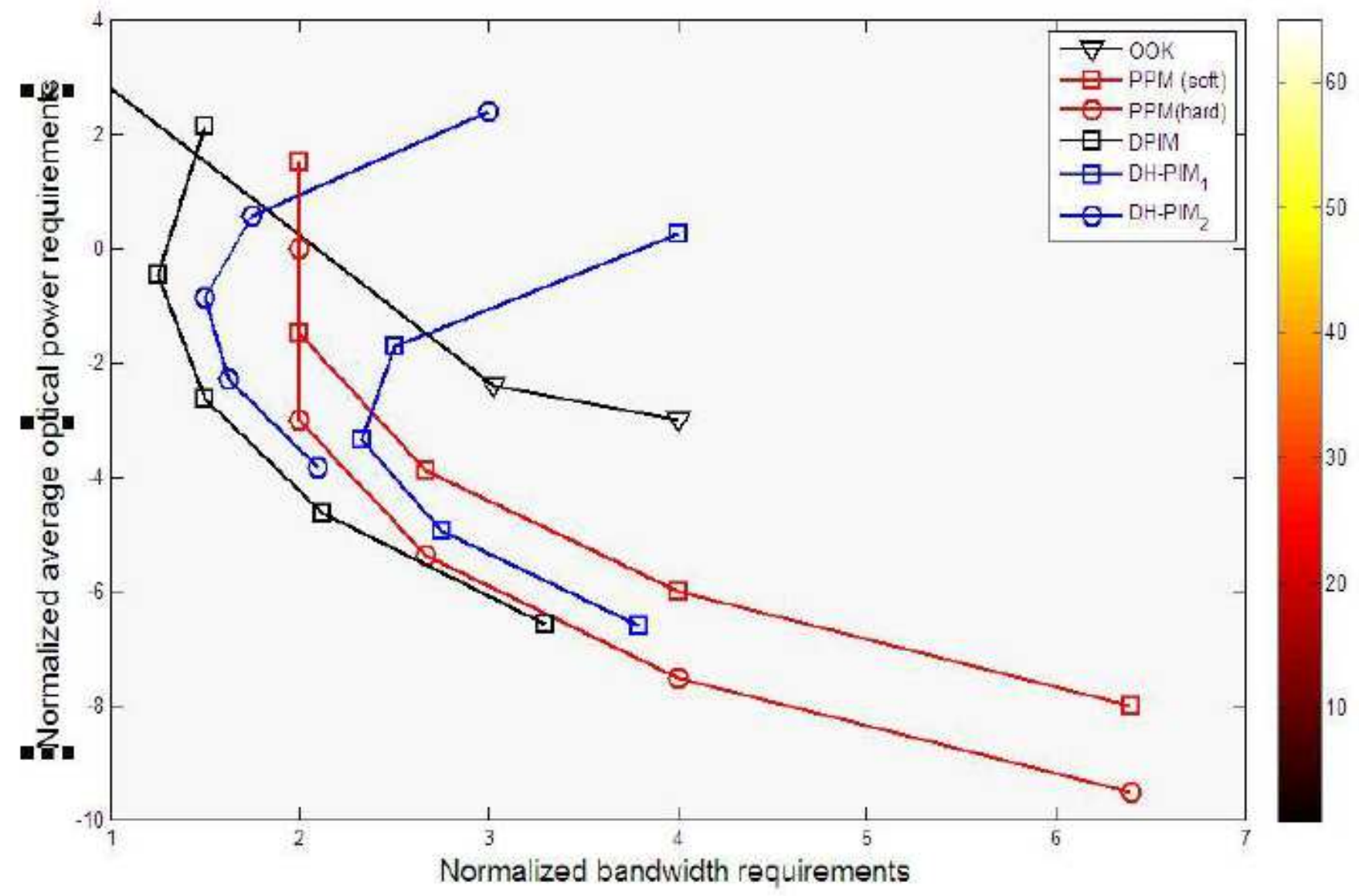

Figure 11

Please see the Manuscript PDF file for the complete figure caption. 


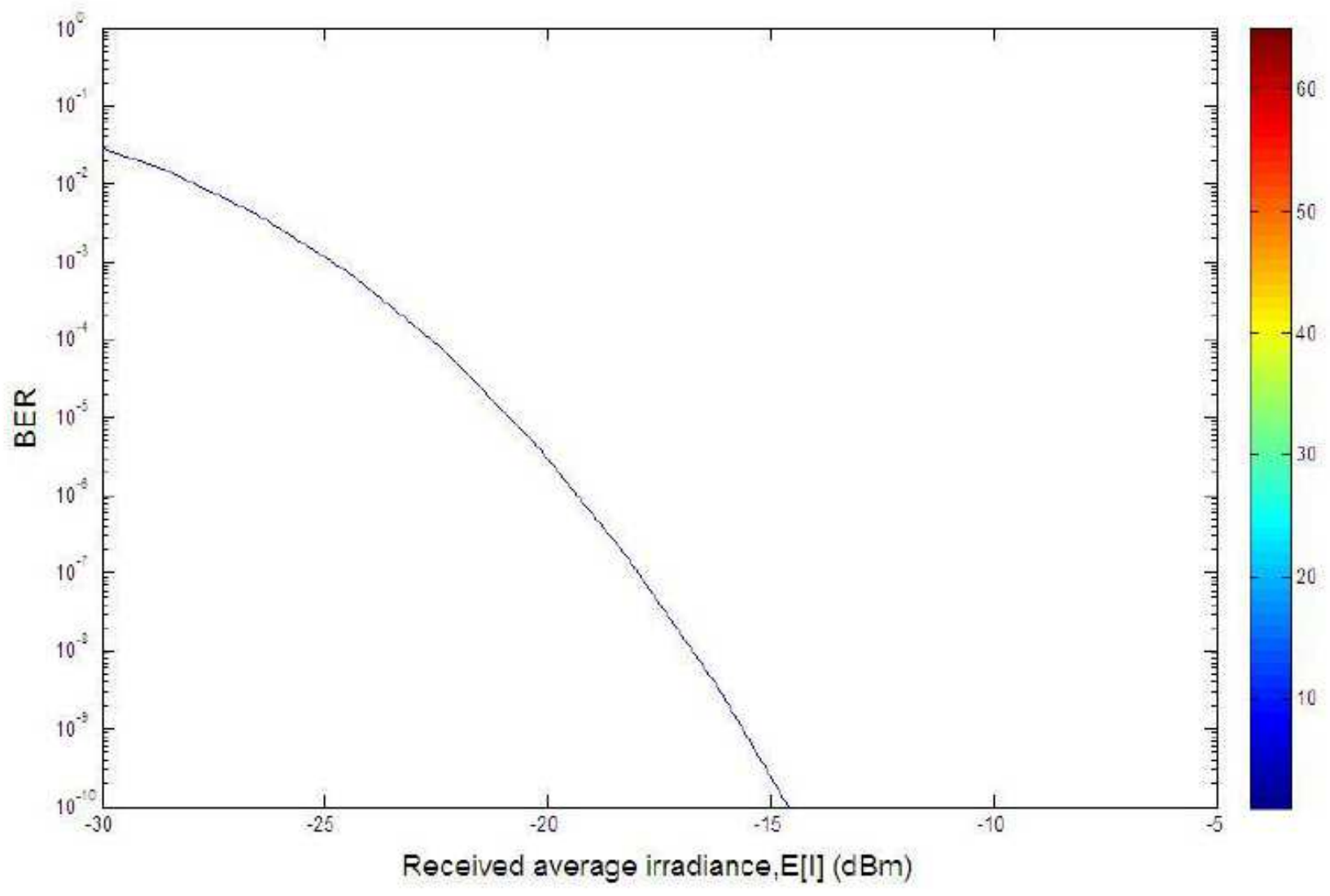

Figure 12

Received average irradiance, E [I] (dBm) VS BER. 


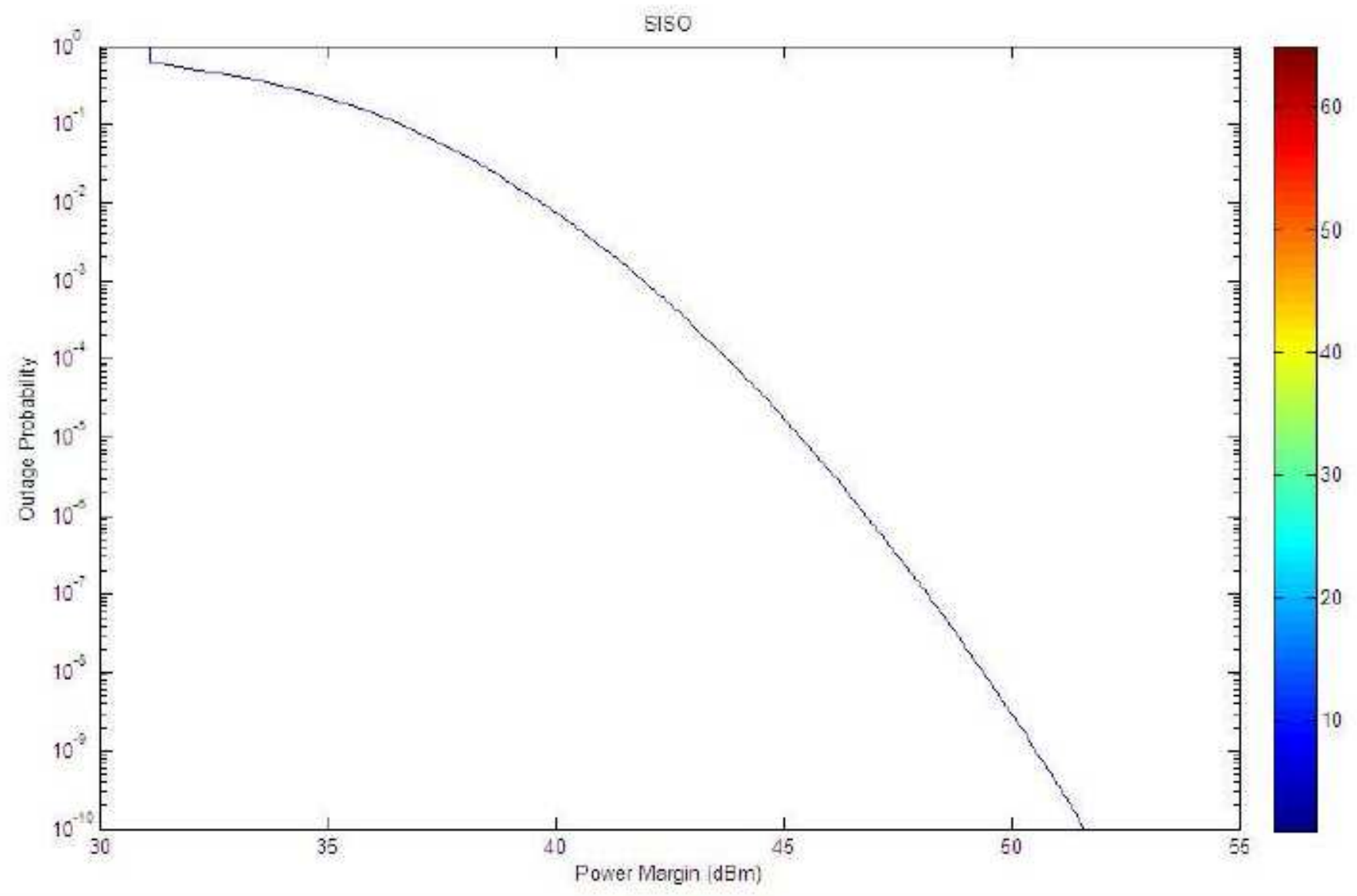

Figure 13

Please see the Manuscript PDF file for the complete figure caption. 


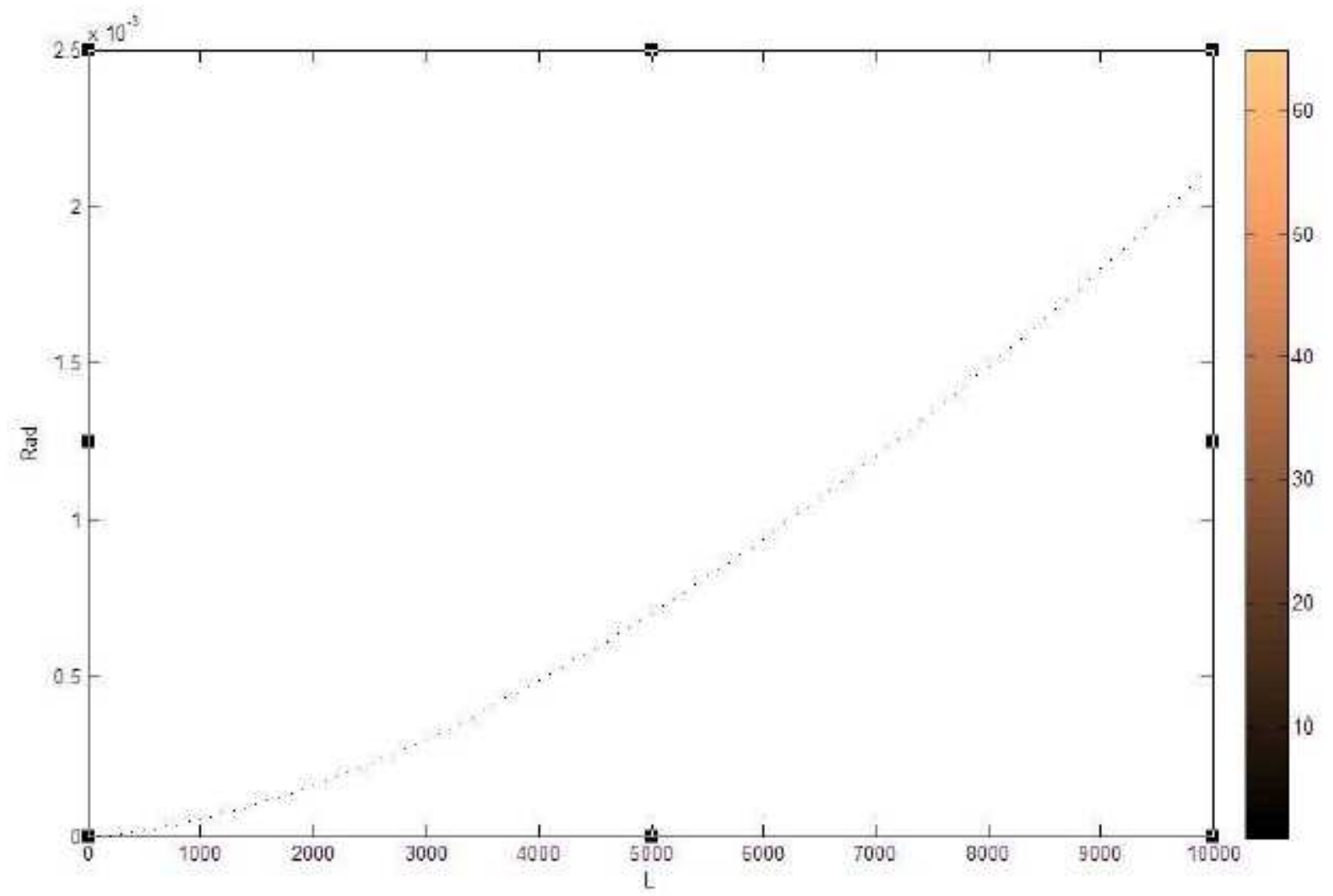

Figure 14

Lfso vs Rad (beam divergence of transmitter ). when $\mathrm{Cn}=8 * 10^{\wedge}(-9)$. 


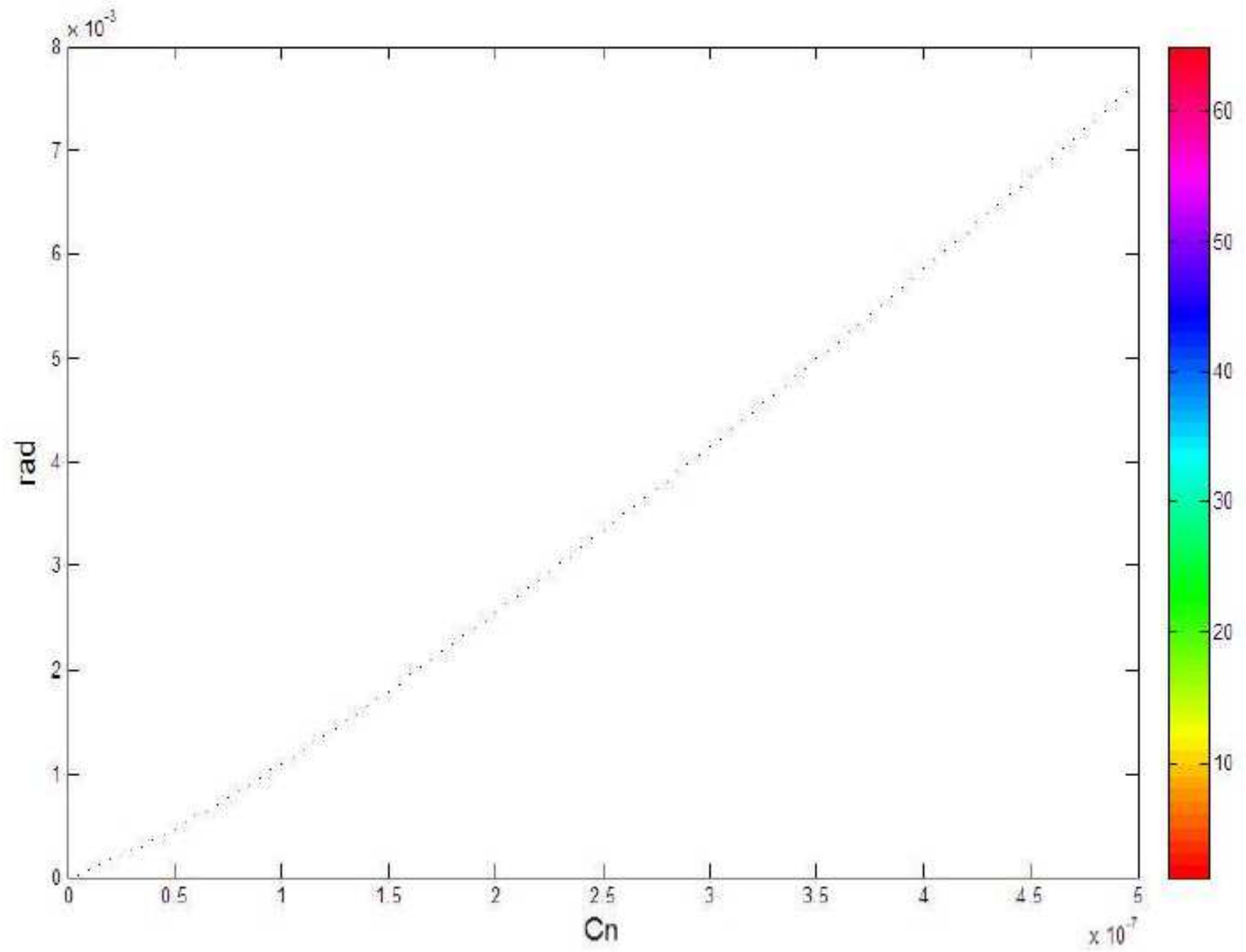

Figure 15

Refractive index strucure vs beam divergence . 


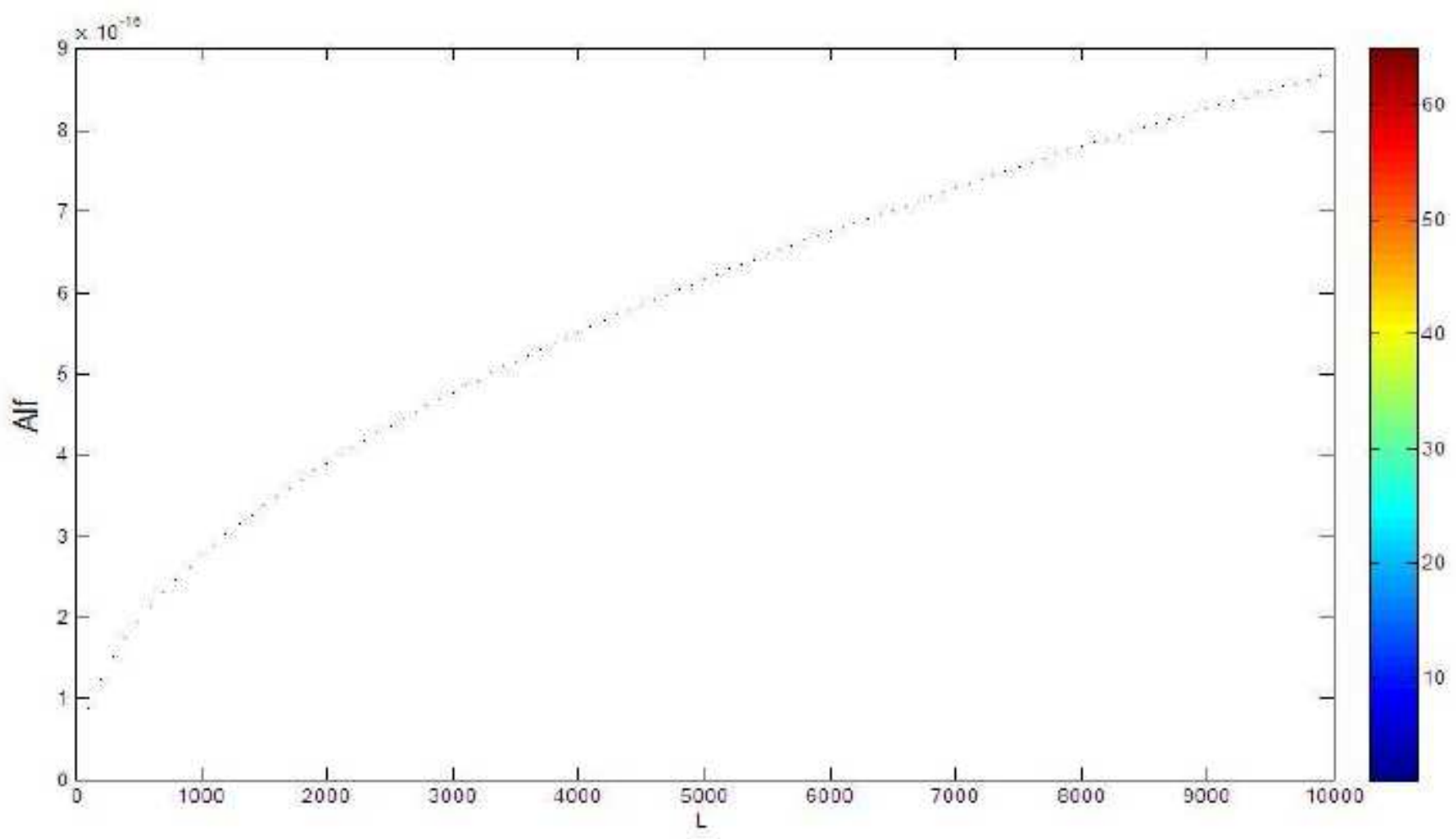

Figure 16

Lfso vs Attenuation (Alfa).

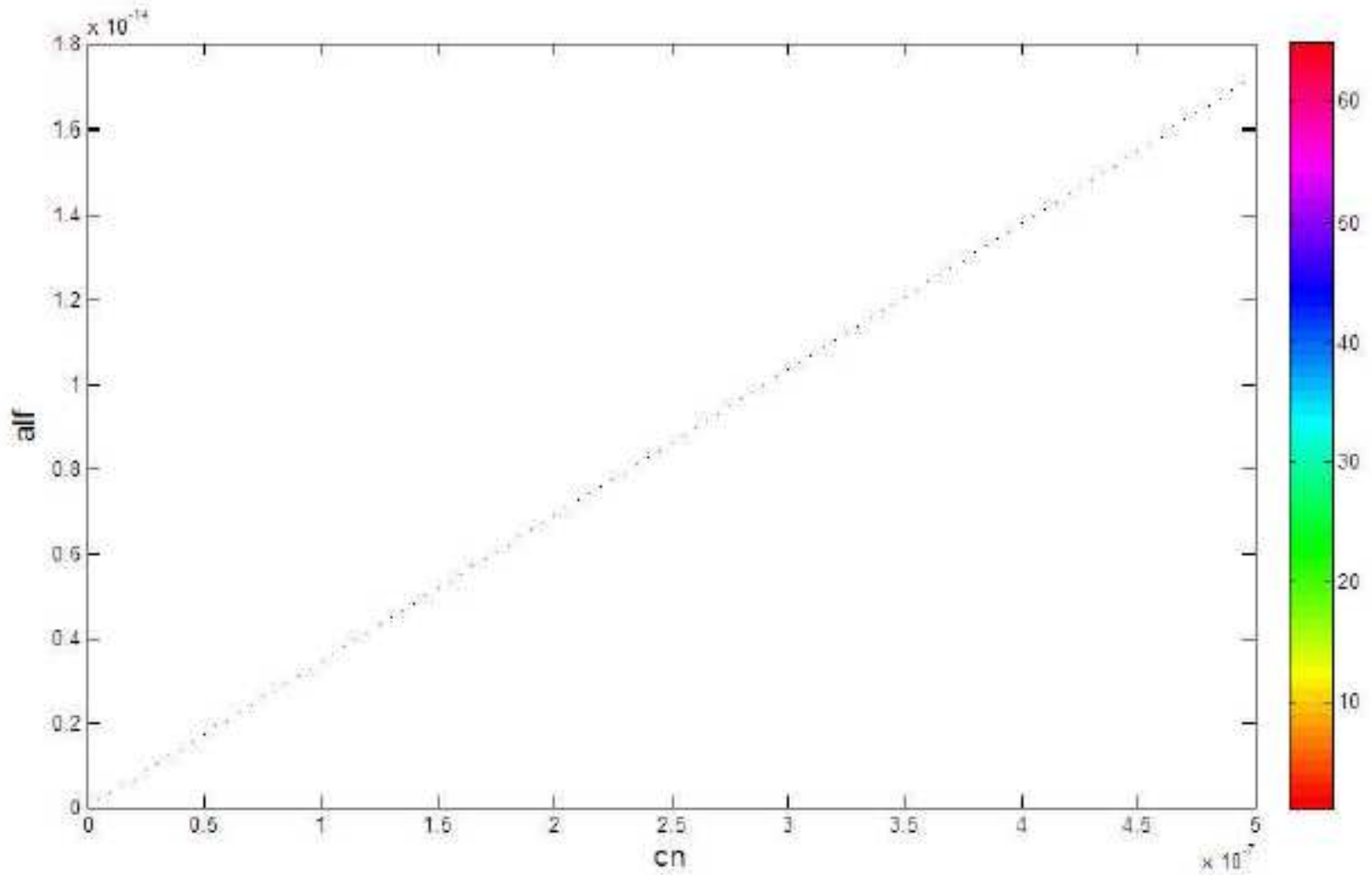

Figure 17 
Refractive index structure vs Alfa.

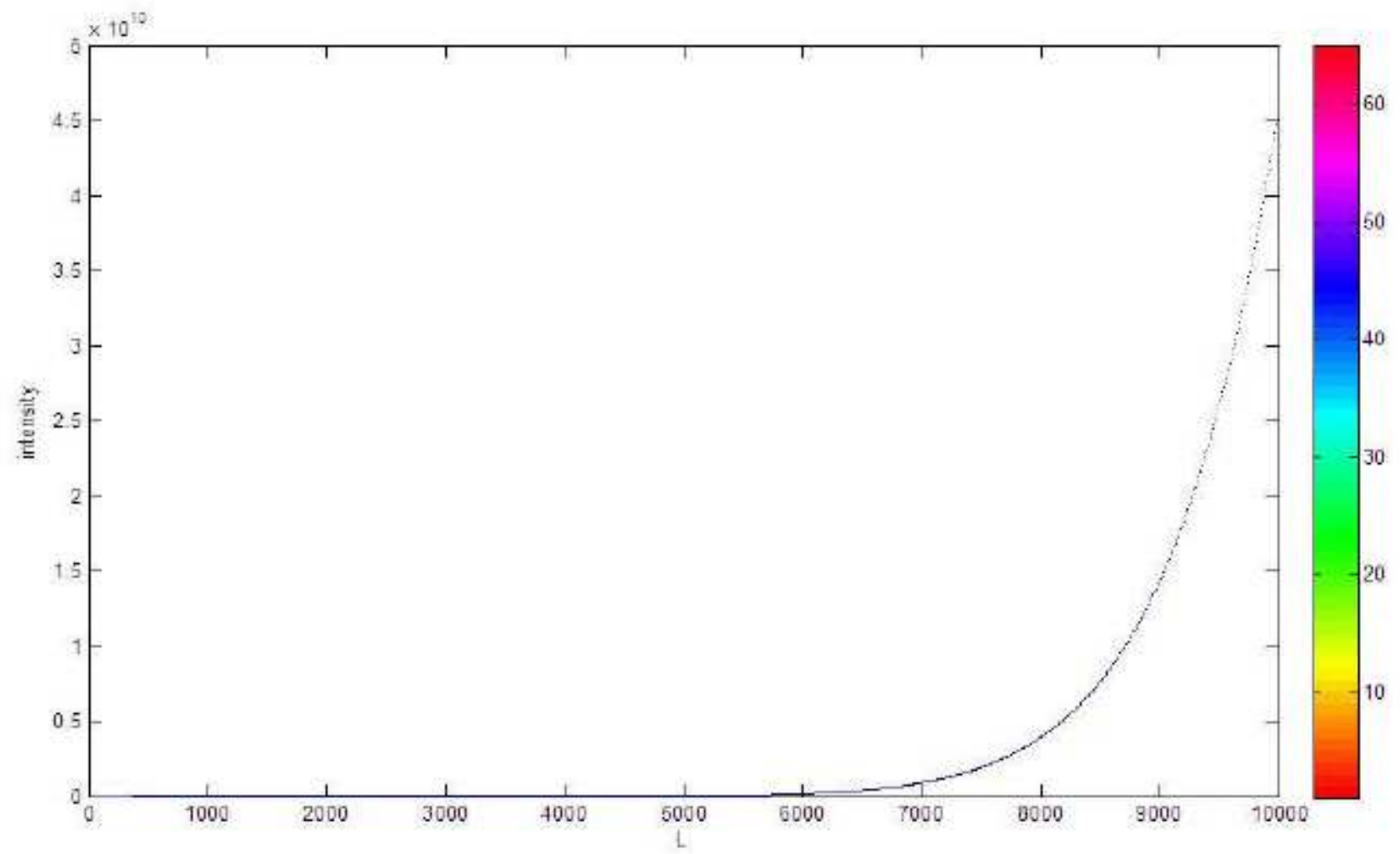

Figure 18

Lfso vs Trubluence intensity. 


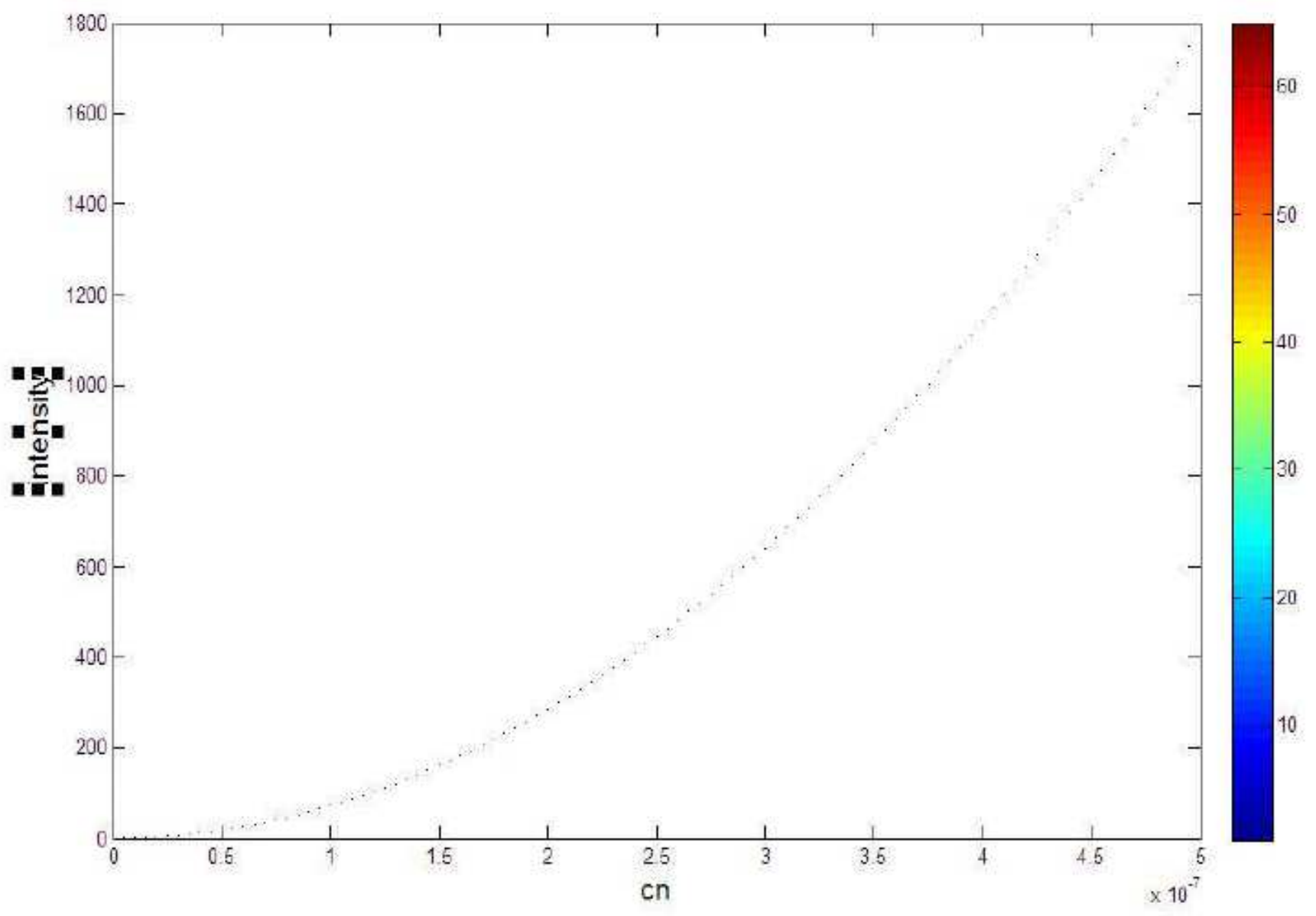

Figure 19

Refractive index structure vs Trublence intensity. 